\title{
Thermal-hydraulic-mechanical (THM) behaviour of a large-scale in situ heating experiment during cooling and dismantling
}

\author{
M. Sánchez, A. Gens, and L. Guimarães
}

\begin{abstract}
A geological disposal facility for high-level radioactive waste (HLW) encompasses both natural (host rock) and (generally clay-based) engineered barriers. Many processes can influence, either positively or negatively, the effectiveness of the safety functions of isolation and retardation. This paper focuses on the analysis of a large-scale heating test when subjected to cooling and subsequent partial dismantling. The experiment reproduces the conditions of an HLW repository at full scale under realistic conditions. Key thermal, hydraulic, and mechanical (THM) variables, such as temperature, relative humidity, stresses, and fluid pressures, were measured in the clay barrier and surrounding rock. The experimental observations recorded during the cooling down and clay barrier excavation are analyzed in light of a fully coupled THM finite element formulation. This analysis has provided the opportunity to explore the behaviour of the clay and natural barriers under conditions very relevant for the repository performance but not analyzed previously. Overall, the model predictions are quite satisfactory when compared against experimental observations. Furthermore, model predictions for a period of 20 years, including the transient phase induced by the partial dismantling, are also presented. This additional analysis has allowed a better understanding of the effect of thermal gradient on long-term clay hydration.
\end{abstract}

Key words: nuclear waste facility, in situ heating test, natural and engineered barriers, cooling, dismantling, long term, numerical analysis.

Résumé : Un dépôt géologique pour l'entreposage de déchets radioactifs de haut niveau (DHN) comprend une barrière naturelle (roche hôte) et une barrière d'ingénierie (généralement à base d'argile). Plusieurs processus peuvent influencer, autant positivement que négativement, l'efficacité des fonctions sécuritaires d'isolation et de retardation. Cet article présente l'analyse d'un essai de chauffage à grande à grande échelle avec un refroidissement et un démantèlement partiel subséquent. L'essai reproduit les conditions d'un dépôt de DHN à l'échelle réelle en conditions réalistes. Les variables thermiques, hydrauliques et mécaniques (THM) clés, comme la température, l'humidité relative, les contraintes et les pressions des fluides, ont été mesurées dans la barrière d'argile et dans les roches environnantes. Les observations expérimentales enregistrées durant le refroidissement et l'excavation de la barrière d'argile sont analysées grâce à une formulation totalement couplée THM par éléments finis. Cette analyse a permis d'explorer le comportement de l'argile et des barrières naturelles dans des conditions très pertinentes pour la performance du dépôt n'ayant pas été analysées auparavant. Globalement, les prédictions du modèle sont plutôt satisfaisantes en comparaison avec les observations expérimentales. De plus, les prédictions du modèle pour une période de 20 ans, incluant la période transitoire causée par le démantèlement partiel, sont aussi présentées. Cette analyse additionnelle a permis de mieux comprendre l'effet du gradient thermique sur l'hydratation à long terme de l'argile.

Mots-clés : dépôt de déchets nucléaires, essai de chauffage in situ, barrière naturelle et d'ingénierie, refroidissement, démantèlement, long terme, analyse numérique.

[Traduit par la Rédaction]

\section{Introduction}

The main aim of a geological repository for high-level radioactive waste (HLW) disposal is to safely contain the pollutant waste for a very long period of time, measured in thousands of years. The host rock (natural barrier) has to provide mechanical stability to the excavated galleries and also be a medium of very low permeability to prevent or retard any possible leakage from the isolation system. The empty space that exists between the waste canister and the cavity surface must be filled with a buffer material (engineered barrier). Expansive clays are generally selected for the construction of these engineered barriers due to their high swelling capacity, very low permeability, and good adsorption ca-

Received 30 October 2011. Accepted 26 June 2012. Published at www.nrcresearchpress.com/cgj on 11 October 2012.

M. Sánchez. Zachry Department of Civil Engineering, Texas A\&M University, College Station, TX, USA.

A. Gens. Department of Geotechnical Engineering and Geosciences, Universitat Politècnica de Catalunya (UPC), Barcelona, Spain.

L. Guimarães. Department of Civil Engineering, Federal University of Pernambuco, Recife, Brazil.

Corresponding author: M. Sánchez (e-mail: msanchez@civil.tamu.edu). 
pacity. These natural and engineered barriers will be subjected to simultaneous thermal, hydraulic, and mechanical (THM) phenomena triggered by the heat-emitting nature of the nuclear waste, the swelling character of the unsaturated clay barrier, and the highly confined conditions of the isolation system. The THM processes described above (and their mutual interactions) will control the evolution and long-term response of the whole isolation system; therefore, a good understanding of the main THM phenomena is required to achieve a safe design of HLW repositories.

Small- to large-scale tests under controlled conditions in the laboratory have been performed in the last few years to investigate the intrinsic properties of the main components of natural and engineered barriers (e.g., Pusch and Karnland 1996; Lloret et al. 2003; Martín and Barcala 2005; Ảkesson et al. 2009). Large-scale in situ tests have been instrumental in examining the behaviour of the barriers system under actual conditions and at full scale (e.g., Volckaert et al. 2000; Dixon et al. 2002; Svemar and Push 2002; Huertas et al. 2006). At the same time, constitutive models and THM mathematical formulations and their respective numerical codes aimed at predicting the behaviour of the isolation system have been developed and validated (e.g., Olivella et al. 1994, 1996; Thomas and He 1995; Rutqvist et al. 2005; Sánchez et al. 2005; Siemens and Blatz 2009; Gens 2010). Recent con-

\section{tributions have confirmed the ab lity of coupled THM sumer-} icar models to reproduce the ob repository near-field (e.g., Rutq desna 2009; Gens et al. 2009: those works, however, focus ma
ent THM behaviour of barriers hydration and heating at
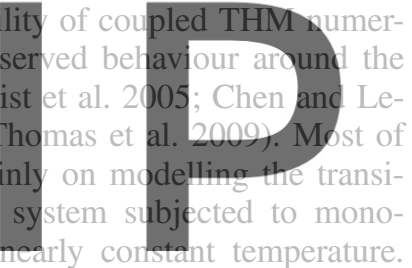
However, during the repository lifetime these conditions may

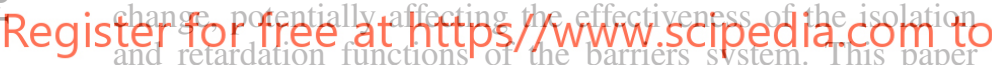
deals with the response of the clay barrier system when subjected to cooling and partial excavation. The availability of experimental observations from the "Full-scale Engineered Barriers Experiment" (FEBEX) in situ heating experiment has provided the opportunity to check the ability of a coupled THM model to predict the behaviour of a barriers system under these more complex conditions, which have not been analyzed in the past.

The full-scale FEBEX in situ test is operated under natural conditions at the underground laboratory at the Grimsel test site in Switzerland, managed by NAGRA, the Swiss National Cooperative for the Disposal of Radioactive Waste (Huertas et al. 2006; Gens et al. 2009). Intensively instrumented and in operation since February 1997, it is the in situ heating experiment that has provided measurements of the main THM variables for the longest period of time. Initially designed with two electrical heaters (that simulate the HLW thermal load), it is currently operating with only one heater because in February 2002 the test was partially dismantled to examine the condition of the barrier components (i.e., bentonite, rock, metals, and instruments) after 5 years of testing (Huertas et al. 2006). A description of the FEBEX in situ experiment, including the analysis of the main variables gathered until a time just before the switching off of heater No. 1 (hereafter referred to as heater\#1) is presented in Gens et al. (2009).

In this paper, the analysis focuses on the effects on the
THM response of the barriers system to the cooling down brought about by switching off of one heater and to the subsequent partial excavation of the barrier, two aspects very relevant to repository design. Numerical predictions from the finite element program CODE_BRIGHT (Olivella et al. 1996) are compared against the experimental observations during this phase. The analysis encompasses both the clay barrier and surrounding granite. In addition, the analysis has been continued to simulate a 20 year period to provide a prediction of the longer-term behaviour of the buffer and adjacent rock.

Thus, this study has provided the opportunity to learn about the THM evolution of the barriers system subjected to a process of decreasing temperature. This behaviour is indeed relevant considering that actual nuclear waste repositories will undergo a cooling down of the system due to the inherent radioactive decay. Obviously, the real process will take place at a very low rate, but the anticipated interactions between the thermal, hydraulic, and mechanical problems expected during the cooling down are expected to be similar to those observed in this phase of the FEBEX in situ test.

There is not yet a consensus about the convenience of designing an isolation system for a "final repository" or a "temporal storage" of the HLW. Until a few years ago, the

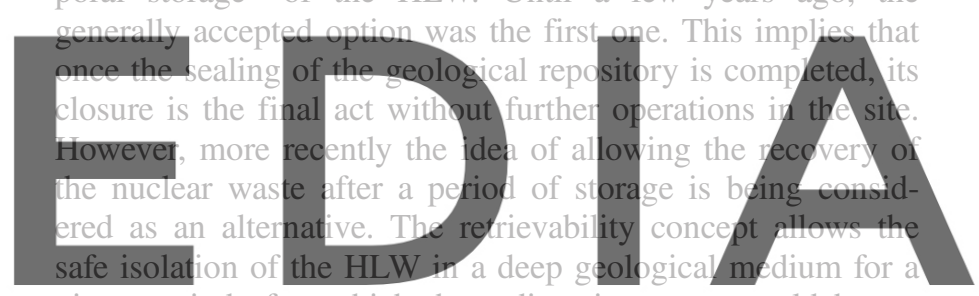
given period after which the radioactive waste could be recovered if a decision to do so were adopted. In this context, downhad the version withod twthenwatermark of heater\#1 provides relevant information about the expected changes in the THM field around the repository during potential retrieval operations.

Furthermore, the placement of new sensors in the part of the clay barrier that is still in operation has offered the opportunity to analyze the effect of temperature gradient on barrier hydration. This is also quite relevant considering the uncertainties concerning the progress of hydration as recently observed in buffer experiments (e.g., Dixon et al. 2002; Thomas et al. 2003; Sánchez et al. 2012). As indicated above, model predictions for a period of 20 years are also presented and discussed; special emphasis is placed on the analysis of sections of the barrier subjected to different thermal gradients.

The paper is organized as follows: ( $i$ ) the main aspects of the in situ testing, cooling, and partial dismantling stages are introduced; (ii) the mathematical formulation and constitutive models and computer code used in the analysis are briefly presented; (iii) the evolution of the experiment until just before the switching off of heater\#1 together with the corresponding numerical model used in the analysis are briefly discussed; ( $i v$ ) the modelling of the cooling phase and excavation activities are described; $(v)$ the long-term analysis is presented. The paper finishes with the main conclusions of the work. Appendix A contains details of the mathematical framework and Table 1 lists the notation used herein. 
Table 1. Notation.

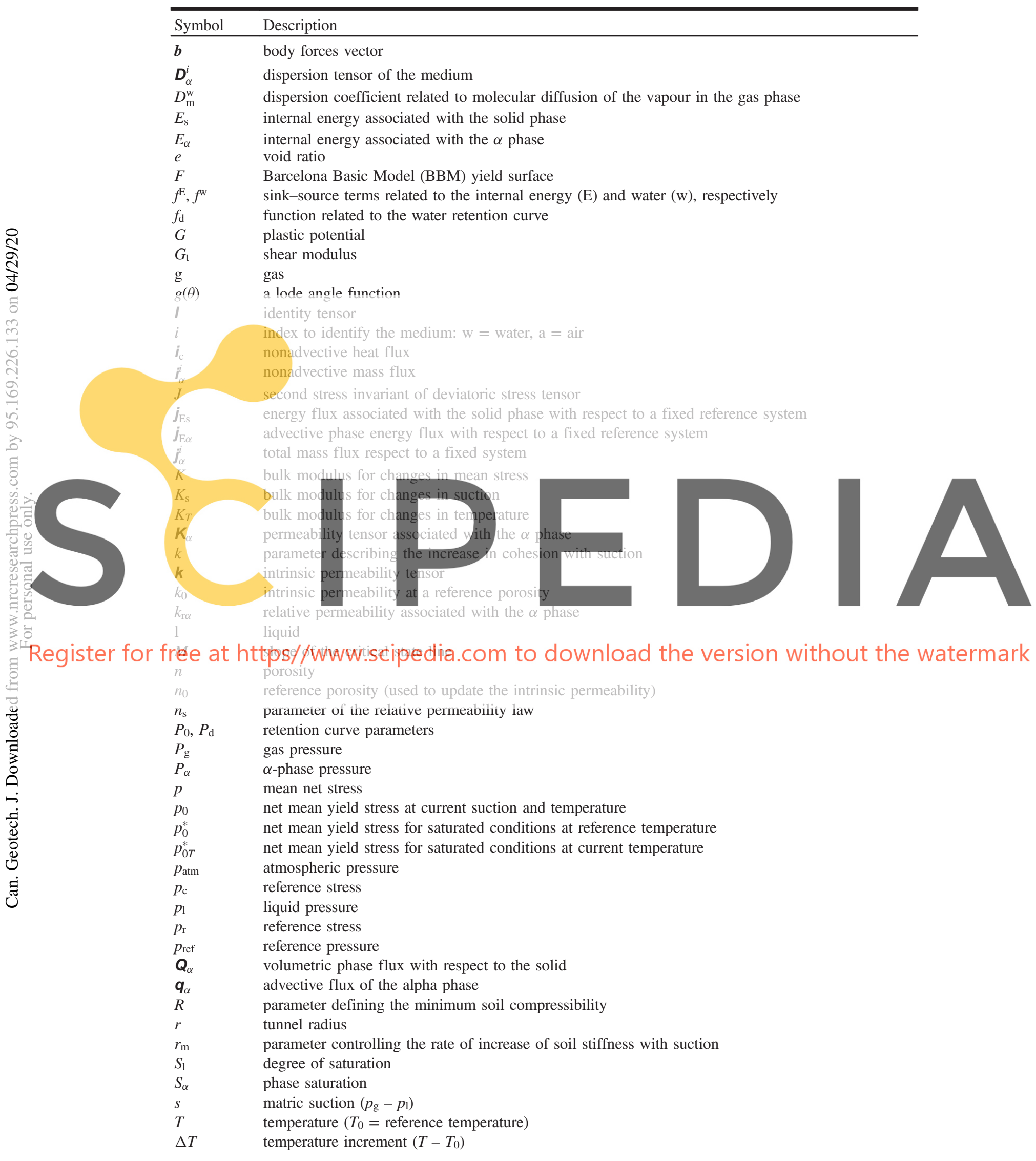


Table1 (concluded).

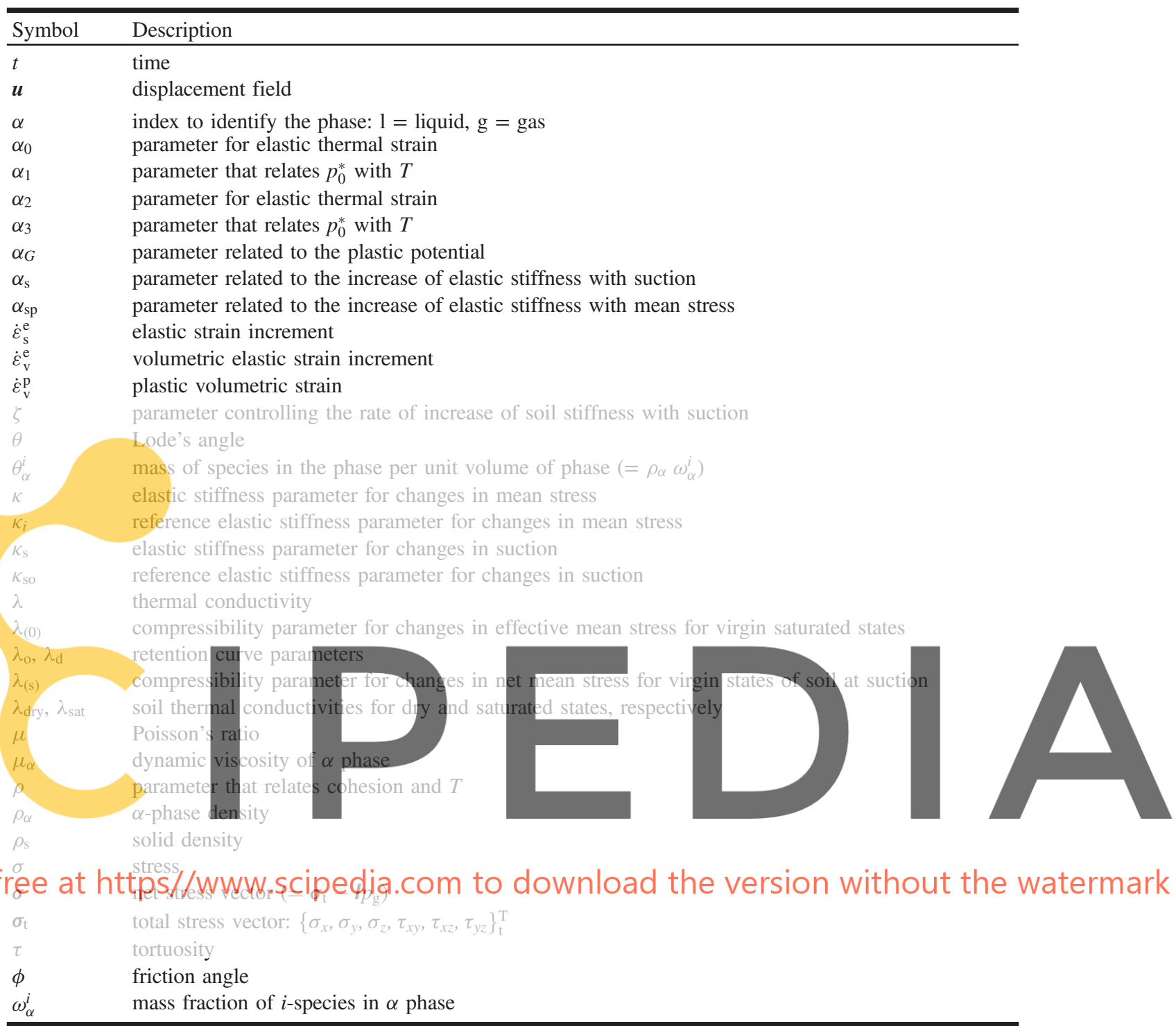

\section{FEBEX in situ test}

\section{Experiment description}

The FEBEX in situ test was designed by the "Spanish Agency for Radioactive Waste Disposal" (ENRESA) to simulate, under realistic full-scale conditions, the Spanish concept for the isolation of high-level radioactive waste. This concept envisages placing the waste-containing canisters in horizontal drifts surrounded by an engineered barrier made up of compacted expansive clay. The host rock is a good quality granite, crossed in the test zone by a lamprophyre dyke. The barrier was built in a $2.28 \mathrm{~m}$ diameter circular tunnel excavated in the Grimsel test site underground laboratory in Switzerland. Two electrical heaters $(4300 \mathrm{~W})$ were placed in the axis of the horizontal drift to simulate the release of heat by the nuclear waste. They were $4.54 \mathrm{~m}$ long and $0.90 \mathrm{~m}$ in diameter, and were intended to mimic the release of heat by HLW. The heaters were surrounded by a $0.69 \mathrm{~m}$ thick clay barrier built with blocks of compacted FEBEX bentonite. The bentonite blocks were compacted to a dry density of
$1.7 \mathrm{Mg} / \mathrm{m}^{3}$ at an average water content of $14.4 \%$. The small gaps between blocks and between the clay barrier and the rock were empty, so the overall dry density of the emplaced barrier was smaller than the original block density, around $1.6 \mathrm{Mg} / \mathrm{m}^{3}$. The adopted design contemplated that during hydration the bentonite will swell, filling all the joints between blocks and the small gaps between the clay barrier and the rock gallery. A $2.7 \mathrm{~m}$ long concrete plug seals the test area. Figure $1 a$ shows the layout of the in situ test.

The experiment is extensively monitored, with sensors installed in the bentonite, granite, heaters, and service zone. The variations of the main THM variables have been recorded in different sections of the clay barrier and in boreholes in the host rock (Fig. 1b). The monitored variables are temperature (in clay barrier and host rock), heater power, relative humidity (in clay barrier), total pressure (in clay barrier and host rock), relative displacement (in clay barrier), fluid pressures (in clay barrier and host rock), among others. More details can be found elsewhere (e.g., Huertas et al. 2006). 
Fig. 2. (a) Intermediate phase of concrete plug demolition and (b) state of a bentonite layer before dismantling.

(a)

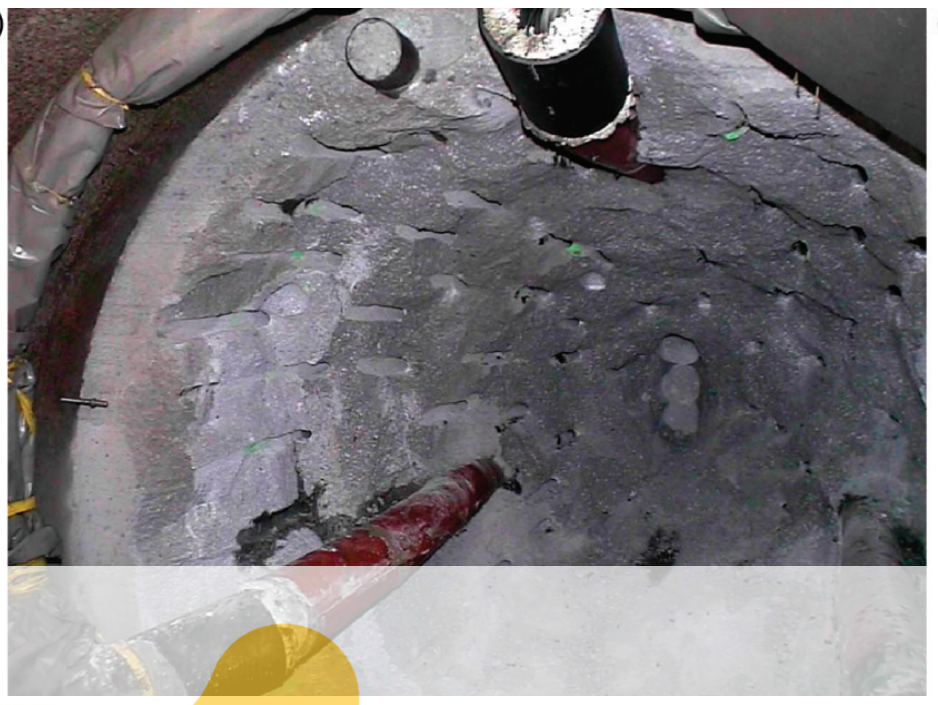

(b)

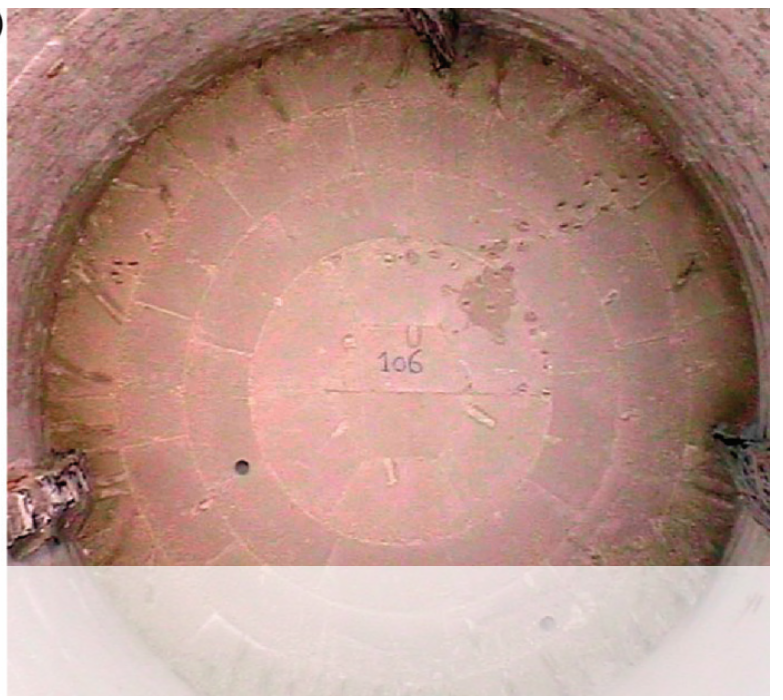

Final experiment configuration and additional instrumentation

Figure $3 a$ illustrates the final layout of the in situ test after the partial dismantling. The clay barrier around heater\#1 was Femoved up to $1 \mathrm{~m}$ before the end of the heater (see detail in
Fig. $3 b$ ). A dummy steel canister with a length of 1 was
inserted in the void left by heater\# in the centre of the buf-
fer. The main objectives of the dummy are to fill this gap and
to kgep the original geometry with material properties (e.g.,
thermal conductivity) similar to the ones existing before the
dismantling.
Before constructing a new concrete plug, additional sensors were installed in the remaining part of the clay barrier.

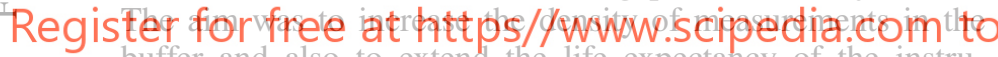
buffer and also to extend the life expectancy of the instrumentation system. The sensors were introduced in boreholes
drilied in the buifer parallel to the divit up to the instrumented section F2 (Fig. 3c). The relative humidity (HR) sensors and the total pressure cells (TPC) were installed in $63 \mathrm{~mm}$ outer diameter plastic pipes. The HR sensors were installed in six plastic pipes, each pipe includes three capacitive relative humidity sensors (model HMP 237 manufactured by Vaisala) located at horizontal distances corresponding to the former instrumented sections G, I, and F2 (Fig. 3a). Two plastic pipes, each including two pairs of Geokon vibrating wire cell pressure sensors located at former instrumented sections I and F2. were also installed. The cells are in contact with the bentonite buffer to measure the total pressure at those points. One cell of each pair was placed in the radial direction and the other is oriented in the circumferential direction. In addition, total pressure cells were installed in the section at the back of the dummy canister (section P, Fig. 3a), identified as "TPC" in Fig. $3 b$.

A new concrete plug was constructed for the necessary confinement of the remaining part of the experiment still in operation. The plug was constructed by shotcreting in two stages. A short $1 \mathrm{~m}$ temporary plug (Fig. $3 a$ ) was constructed just after dismantling. The final one ( $3 \mathrm{~m}$ long) was placed after installing the new instrumentation. A more detailed description of all the activities performed during the partial dismantling of the in situ test can be found in Barcena et al. (2003).

\section{Mathematical formulation and computer code}

Several strongly coupled THM phenomena take place when an unsaturated clay barrier is subjected to simultaneous

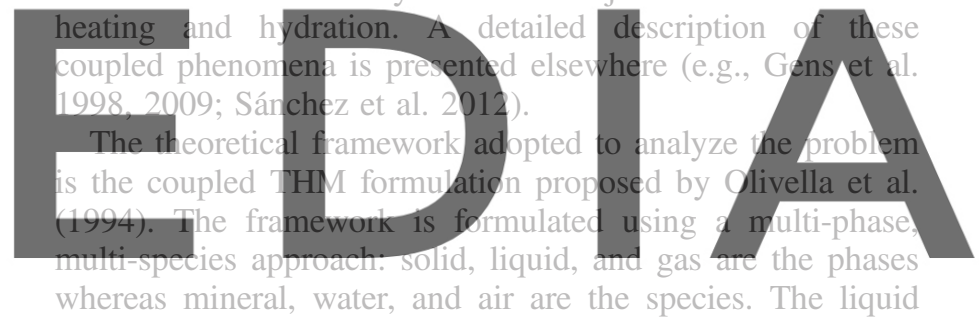

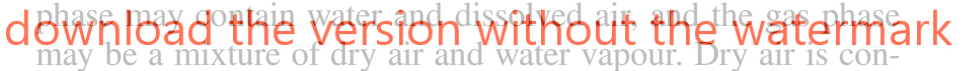
sidered as a single species.

The approach is composed of three main parts: (i) balance equations, (ii) constitutive equations, and (iii) equilibrium restrictions. The main balance equations considered in the formulation are mass balance of species (i.e., water, air, and solid), balance of internal energy, and momentum balance. One main (state) variable is associated with each balance equation. For example, liquid pressure $\left(P_{1}\right)$ is associated with water mass balance, temperature $(T)$ with internal energy balance, and displacements $(\boldsymbol{u})$ with momentum mass balance. The constitutive equations establish the link between these main (state) variables and the dependent variables; among others, degree of saturation $\left(S_{1}\right)$; stresses $(\sigma)$, heat flux $\left(\boldsymbol{i}_{\mathrm{c}}\right)$. A short description of the mathematical formulation and main constitutive models is presented in Appendix A. Figure 4 presents experimental results (symbols) of the FEBEX bentonite related to the main constitutive equations together with the relationships used in the analyses (lines). Figure $4 a$ presents results related to the mechanical model. In that figure the experimental data was obtained from swelling pressure tests (reported in Lloret et al. 2003) and the model results correspond to eqs. [A4] to [A15c] (see Appendix A and Table 3 ). Figure $4 b$ presents the variation of intrinsic permeability (determined under saturated conditions) in terms of porosity. The experiments were performed with samples under constant saturation (Villar 2002) and a modified 
Table 2. Dismantling operation sequence.

\begin{tabular}{llc}
\hline Step & Description & Duration (days) \\
\hline 1 & Switching off of heater\#1 & $33^{*}$ \\
2 & Rock sampling in the service area & 3 \\
3 & Demolition of the concrete plug and sampling & 56 \\
4 & Removal of bentonite up to the front of the first heater and sampling & 20 \\
5 & Extraction of heater\#1 & 1 \\
6 & Removal of liner and bentonite buffer and sampling & 28 \\
7 & Installation of the new instruments & 5 \\
8 & Insertion of a 1 m dummy steel cylinder in the central hole & 0.5 \\
9 & Construction of the first section of the shotcrete plug & 2 \\
10 & Installation of additional instruments in the buffer & 1 \\
11 & Completion of the shotcrete plug to a total length of $3 \mathrm{~m}$ & 5 \\
\hline
\end{tabular}

*Before plug demolition.

Fig. 3. (a) Scheme of the in situ test after dismantling indicating the position of the boreholes for additional instrumentation, (b) detail of new concrete plug and dummy canister, and (c) drilling machine used to drill the new sensor boreholes (modified after Barcena et al. 2003).

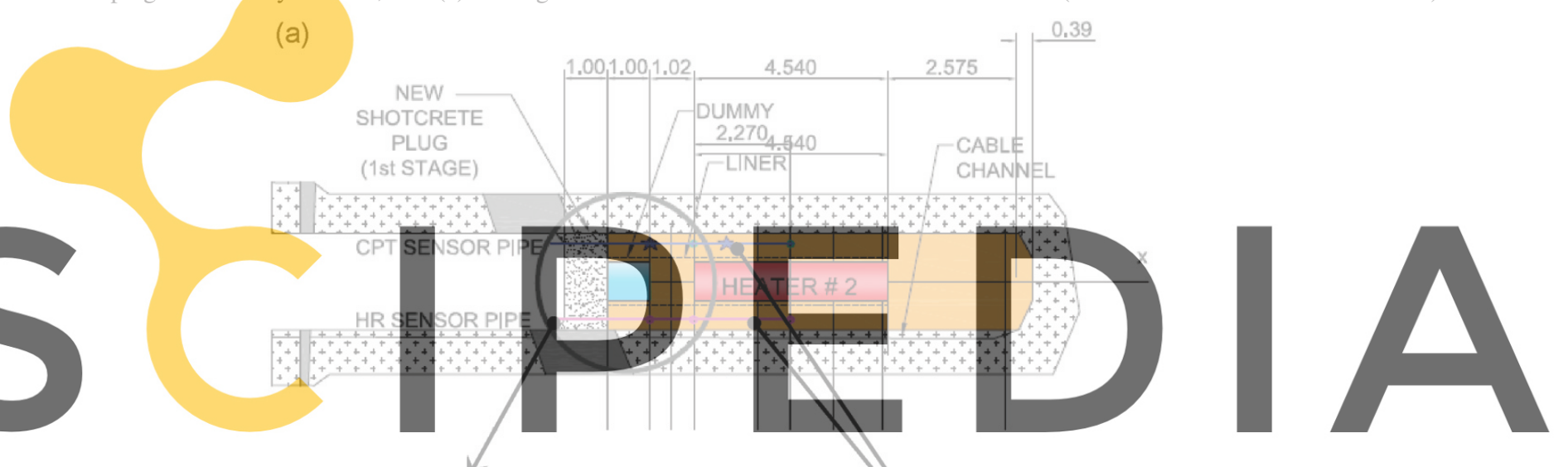

Register for free at https//www.scipedia.com to download the version without the watermark
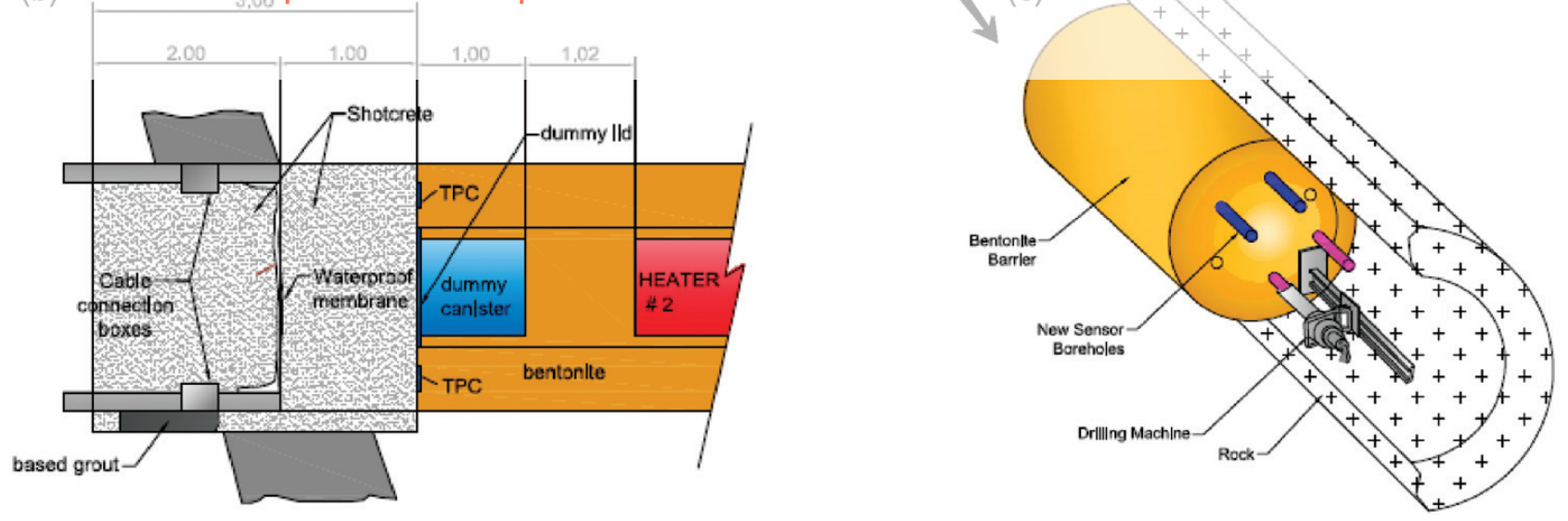

Kozenny's law (eq. [A18]) has been used in the simulations. Results related to water retention tests performed under constant volume conditions (Villar 2002) are presented in Fig. $4 c$; alongside the model outputs obtained from a van Genuchten's (1978) modified law (eq. [A19]). Figure $4 d$ presents results concerning thermal conductivity and the associated adopted model (eqs. [A23a] and [A23b]).

The main model parameters associated with the constitutive models of the different components of the barrier system are presented in Table 3. As mentioned in the section titled
"Experiment description", in the test zone the granite is crossed by a lamprophyre dyke. As would be expected, there are significant variations of permeability in different zones of the rock, depending on the degree of fracturing and the presence of contacts with the lamprophyre dykes. However, it has turned out that these local variations did not affect the performance of the test, because the low permeability of the bentonite controlled the rate of water ingress; effectively, all parts of the granite supplied sufficient amounts of water along the whole test area (Gens et al. 2009). The lampro- 
Fig. 4. Main constitutive laws. (a) Mechanical: computed stress path for swelling pressure tests using the Barcelona Basic Model (BBM). Experimental results (SP1 and SP2 paths) are provided for comparison. (b) Hydraulic: variation of saturated permeability with porosity. Experimental data and adopted model for the intrinsic permeability law. (c) Hydraulic: retention curve adopted in the analyses, together with the experimental data for FEBEX bentonite (symbols). (d) Thermal: thermal conductivity. FEBEX bentonite experimental results (symbols) and model fitting.
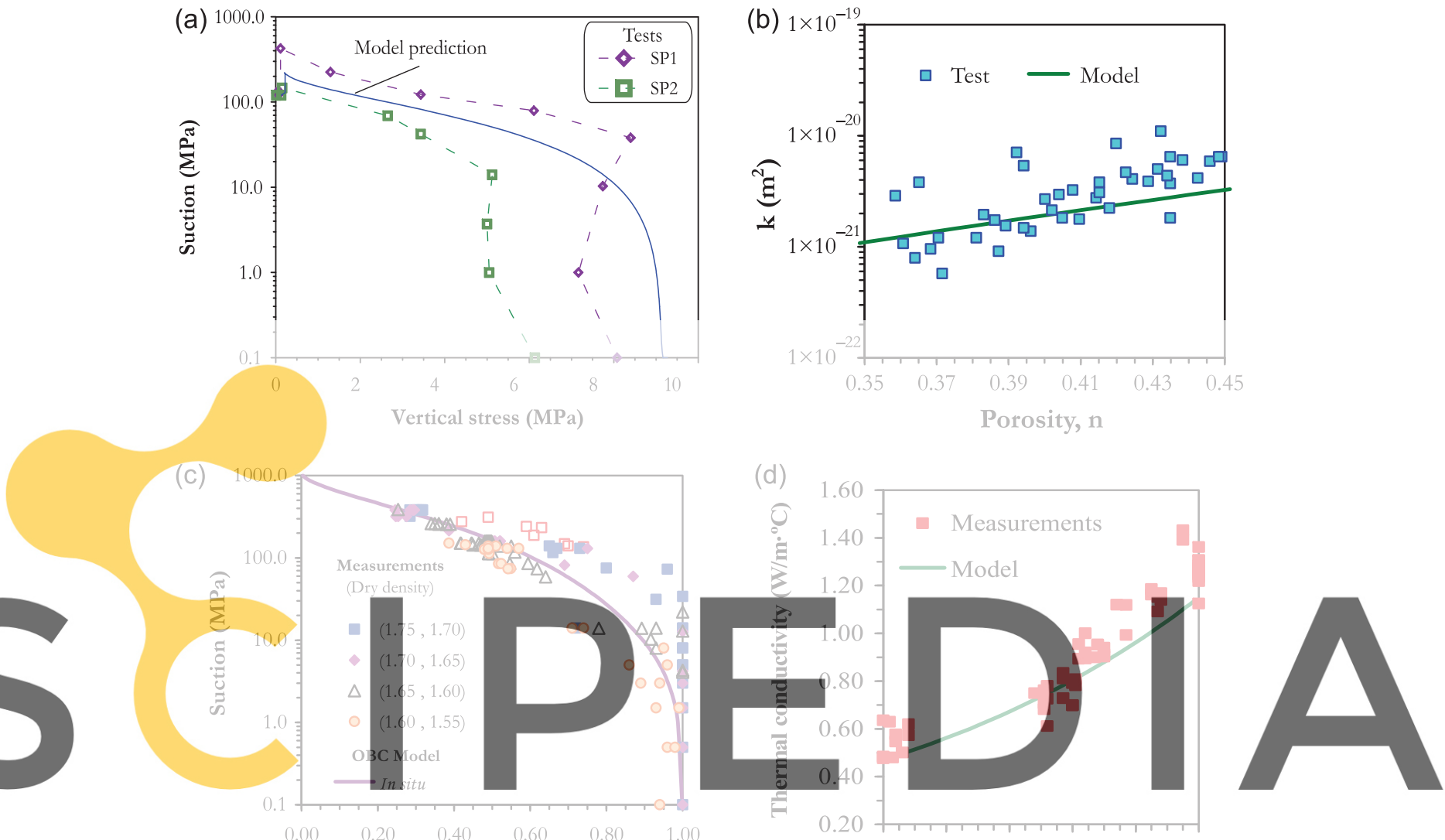

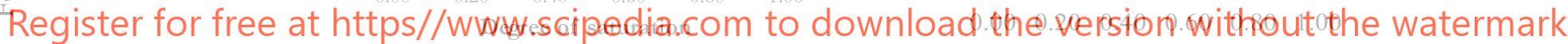 \\ Degree of saturation}

phyre has not been (explicitly) included in the model, and the values quoted in Table 3 are related to average properties for the test section. Because there was no evidence of desaturation of the rock, the granite was assumed to be saturated throughout.

Based on the above coupled formulation, the finite element program CODE_BRIGHT was developed (Olivella et al. 1996). All the equations (i.e., mass balance, momentum balance, constitutive and equilibrium restrictions) are solved in a fully coupled way. The Newton-Raphson method is used to solve the nonlinear problem and finite differences are adopted to solve the evolution in time. The code has been extensively validated in different simulations involving coupled geomechanical problems (e.g., Olivella et al. 1996; Alonso and Alcoverro 2005; Sánchez et al. 2008, 2012; Gens et al. 2009).

\section{Modeling the in situ test until the switching off of heater\# 1}

To provide a suitable background to the work reported in this paper, the analysis of the THM behaviour of the test until the switching off of heater\#1 is summarized in this section. The numerical analysis presented corresponds to the model coded as the "operational base case" (OBC). The
OBC model attempts to incorporate all available information obtained from the laboratory test of FEBEX bentonite at the beginning of the operational stage. In fact, the analysis and test overlapped for a few months but no adjustments were made later on. The analyses are compared with observations over a 5 year period; therefore, the analysis results reported herein can be considered, to a large extent, predictions.

The model results presented in this section include two main phases of the experiment: $(i)$ an initial isothermal hydration of the barrier taking place in the 135 day period between the sealing of the drift and the start of heating and (ii) simultaneous (natural) hydration and heating of the test with the two heaters switched on lasting 1827 days.

Figure 5 shows the two-dimensional axisymmetric longitudinal section adopted for the modelling of the in situ test. A number of analyses were performed to study the sensitivity of the model results with respect to $(i)$ the adopted mesh (i.e., element size, discretization, element shape) and (ii) distance to the boundaries. Based on those analyses, a mesh composed of 2387 quadrilateral bilinear elements with four integration points has been adopted in this study. Selective integration according to Hughes (1980) has also been adopted. The outer boundary of the model is placed at a distance of $50 \mathrm{~m}$ from the tunnel axis. The geometry also takes 


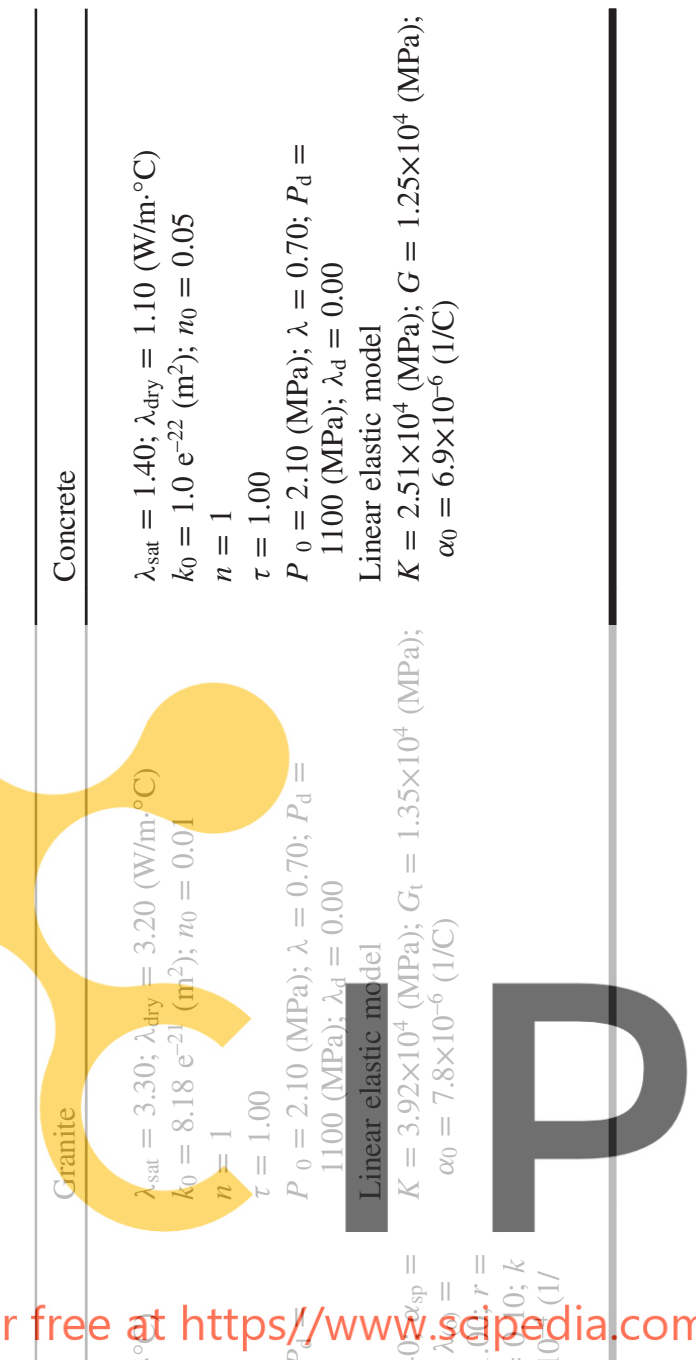

Register for free at https//www. șe pedia 
Fig. 5. Two-dimensional axisymmetric mesh of the in situ test. $x$-axis is coincident with the tunnel axis and $y$-axis is in the direction of the tunnel radius, $r$. (a) Detailed mesh involving the different materials to be excavated and the ones that will remain in the mesh; $(b)$ whole mesh. All dimensions in metres.

(a)

$$
2.70
$$

4.325

4.540

$1.02 \quad 4.540$

2.575

\subsection{4}

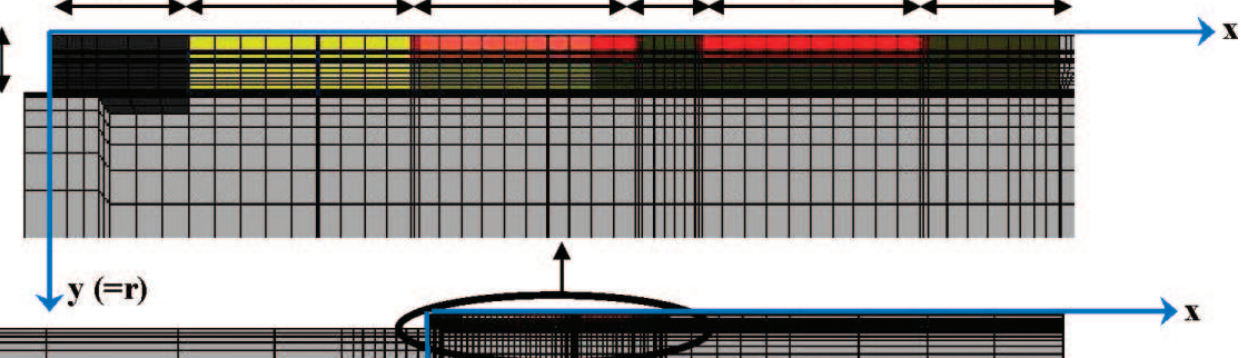

(b) $\quad$ y $(=\mathbf{r})$
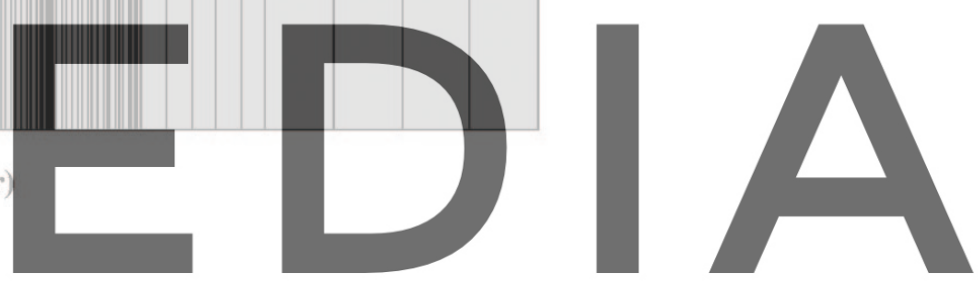

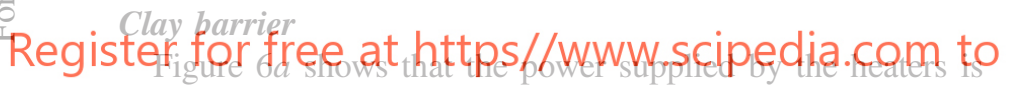
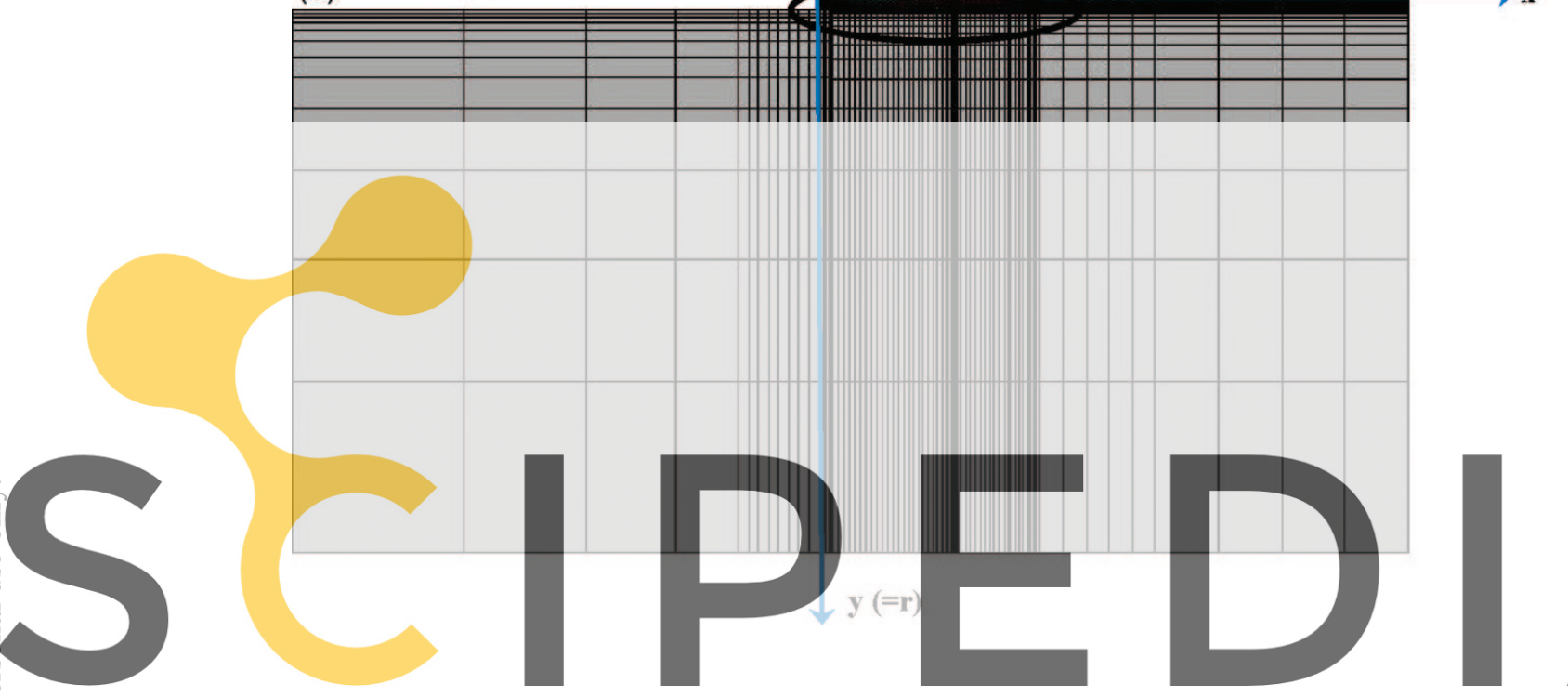

slightly underpredicted at advanced stages of the experiment (by around 10\% in heater\#1). In spite of this, the model captures well the overall thermal trend of the test. As an example, the comparisons corresponding to section D2 are presented in Fig. $6 b$.

The presence of heterogeneities in the natural system may make it more difficult to predict the hydration of the clay barrier correctly. Nevertheless, the response of the model is globally satisfactory. As an example, results from "section E1" are presented in Fig. $6 c$. In the zone near the rock there is a monotonic increase of relative humidity, reflecting the process of hydration induced by the host rock water. The behaviour close to the tunnel axis is characterized by an initial increase of the relative humidity (induced by the passing of a vapour front driven by heating) followed by drying, and then by a gentle increase of relative humidity due to the progress of the general hydration. In general terms, and considering also other sections of the barrier, the correspondence between computations and measurements is quite good although at some points near the heater the observed drying is somewhat stronger than computed.

As expected, a significant increase of stresses has been observed during hydration. This is due to the confined conditions of the clay barrier and the high swelling potential of the heavily compacted bentonite (Fig. 6d). The measurement of total stresses in an in situ test is quite complex (e.g., it is

downh to achieve good contact between materials, so it is sults. At the beginning, the model results appear to provide an upper bound to measurements that could be consistent with the fact that stress cells started giving meaningful readings sometime after the start of the test.

\section{Host rock}

The thermal field is also quite well captured in the host rock. Typical results are presented in Fig. $7 a$. The slight underprediction of temperatures observed in the clay barrier persists in the rock mass. Water pressure recovery in the rock is also well described by the model (Fig. 7b). Pressure values are of the correct order of magnitude and, in particular, rates of pressure recovery are captured well. Measured radial displacements in the rock are very small (of the order of $0.1 \mathrm{~mm}$ ) making it difficult to discern a clear trend (Fig. 7c). Overall, the model also predicts small displacements, although somewhat larger than the measured ones. Finally, uncertainties also affect total stress measurements in the rock (Fig. 7d). However, stresses computed in the numerical analysis appear to provide a satisfactory estimate of the magnitude of the observed stress increases.

It can be concluded, therefore, that the thermal-hydraulicmechanical behaviour of the experiment is well captured overall by the model during heating in both the clay barrier and host rock. In the following section the behaviour under cooling is analyzed in detail. 
Fig. 6. Evolution of main variables in the clay barrier, observed versus computed values (OBC model): $(a)$ heat power; $(b)$ temperature; (c) relative humidity; $(d)$ stresses.
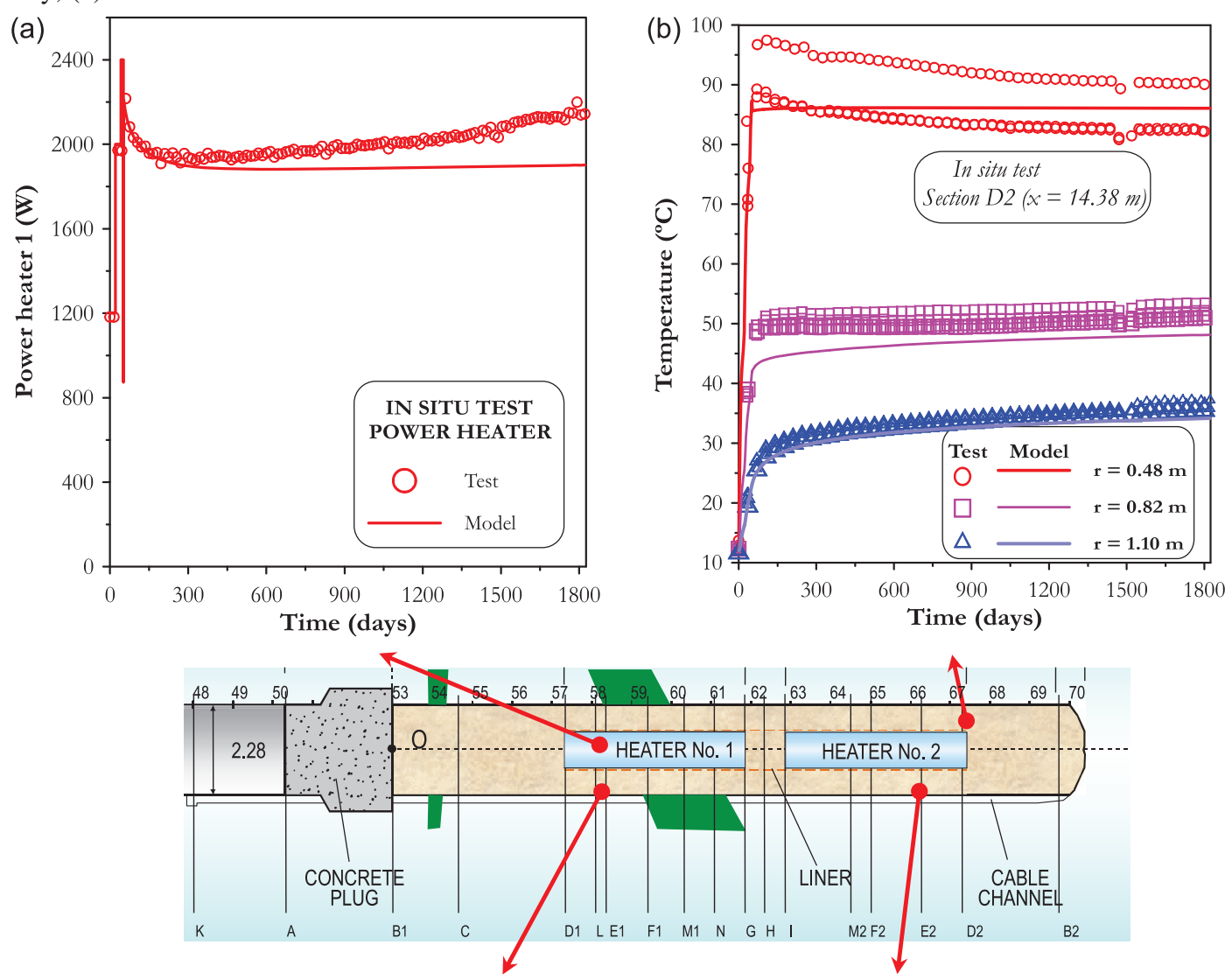

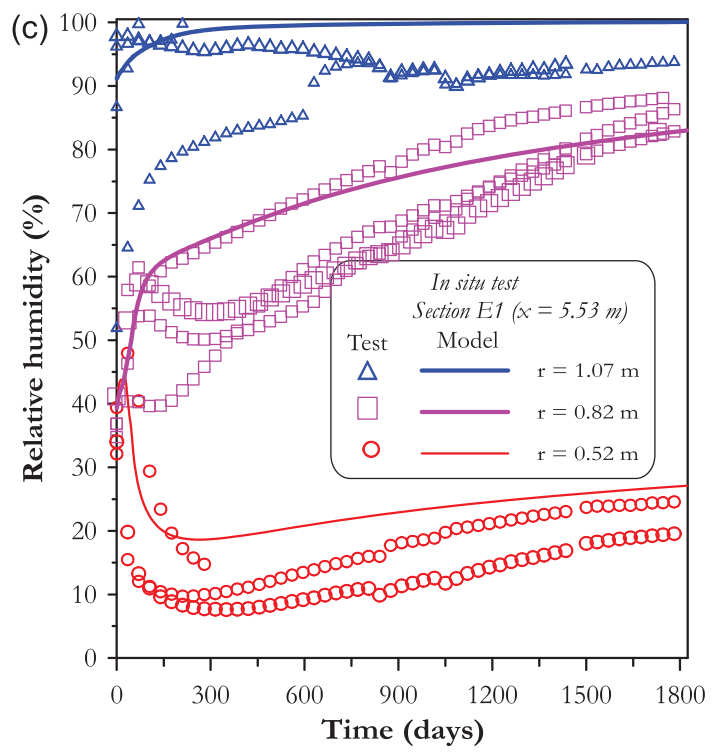

\section{Cooling down and partial dismantling modelling}

\section{Cooling down of heater\#1 simulation}

Based on a number of preliminary numerical analyses, it was decided to switch off heater\#1 in one step. It was predicted that after about 1 month of heater\#1 disconnection, the temperature in the sections of the barrier to be retrieved would be suitable to conduct the dismantling operations. Fig-

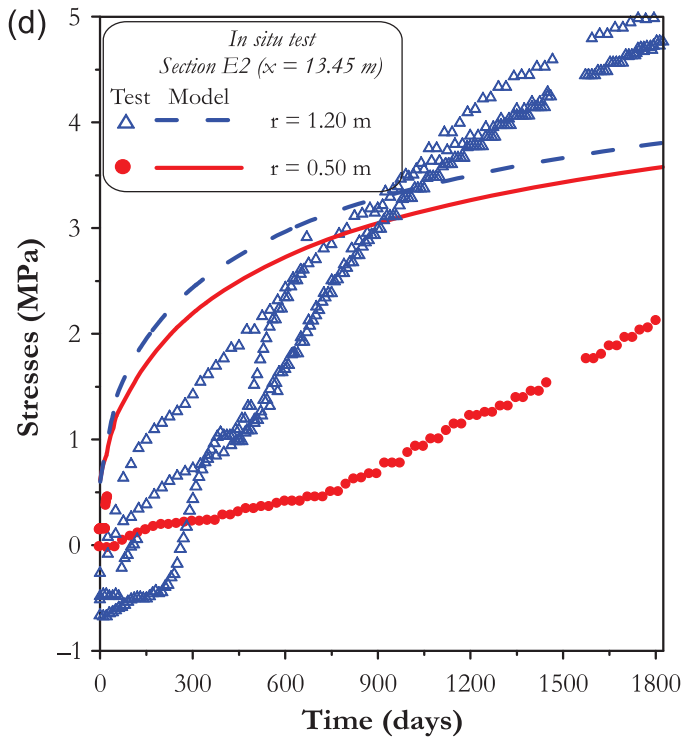

ure $8 a$ presents the thermal field just before switching off heater\#1, and Fig. $8 b$ shows it 1 month later.

Figure 9 shows experimental and modelling results of the evolution of the temperature at the heater-bentonite interface contact point where the temperature was previously fixed at $100{ }^{\circ} \mathrm{C}$. This figure also presents the power emitted by heater\#1; the model slightly underpredicted (as explained before, by approximately 10\%) the heater power. Up to day 1827 (28 February 2002) the heating power was adjusted au- 
Fig. 7. Evolution of main variables in the clay barrier, observed versus computed values (OBC model): $(a)$ temperature; $(b)$ liquid pressure; (c) radial displacement; $(d)$ stresses.
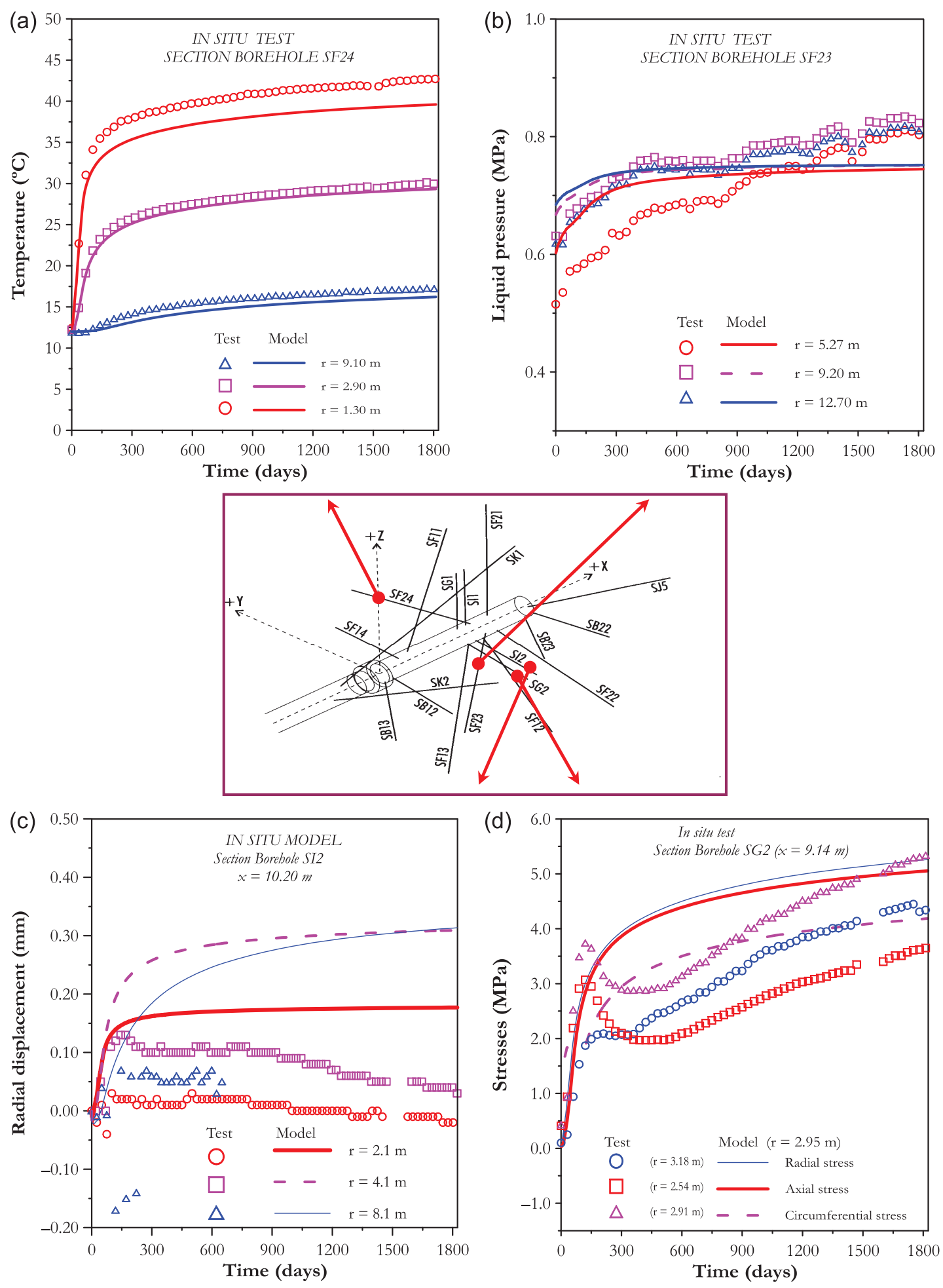

tomatically to maintain a constant temperature of $100{ }^{\circ} \mathrm{C}$ at the interface between the heater and the bentonite. From this date on, heater\#1 was switched off and this zone of the barrier cooled down as recorded by the sensor. The model was able to predict very well the temperature decay at the thermal control point.

\section{Partial dismantling simulation}

The simulation of the different operations involved in the partial dismantling of the in situ test required the development of a new excavation module in CODE_BRIGHT. The implemented algorithm is based on the removal of the elements to be excavated from the mesh just before excavation 
Fig. 8. Contours of temperature (a) just before the switch-off of heater\#1 and $(b)$ just before the plug demolition.

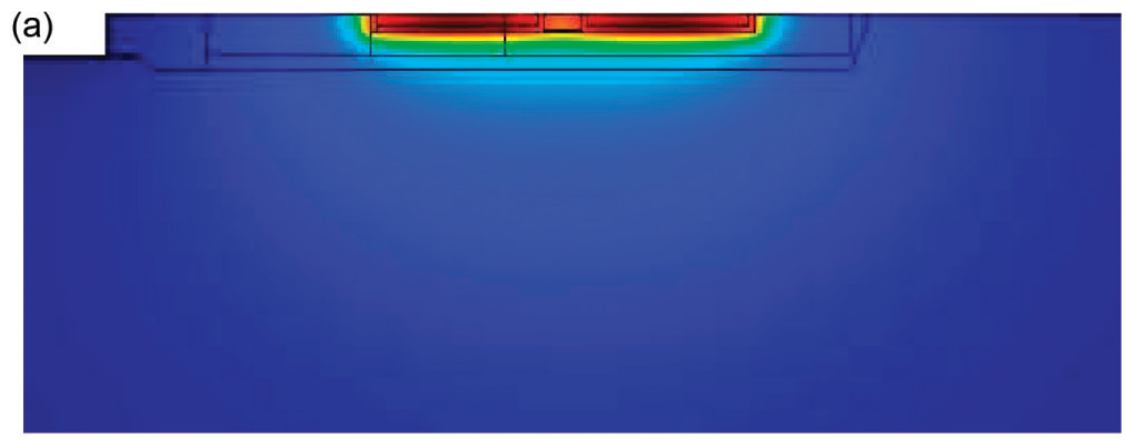

\section{(b)}

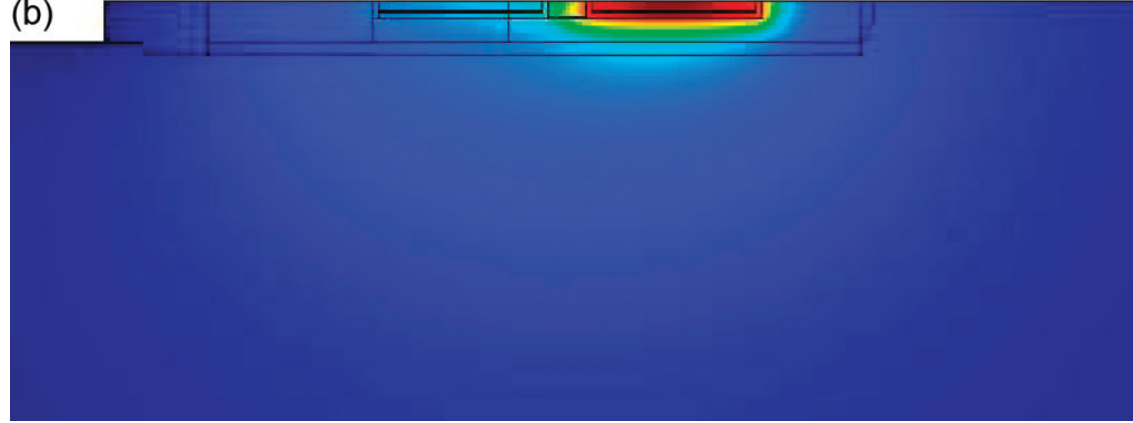

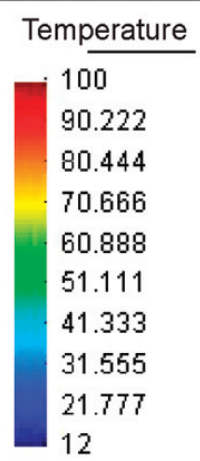

Fig. 9. Evolution of temperature and power of heater\#1 during cooling.
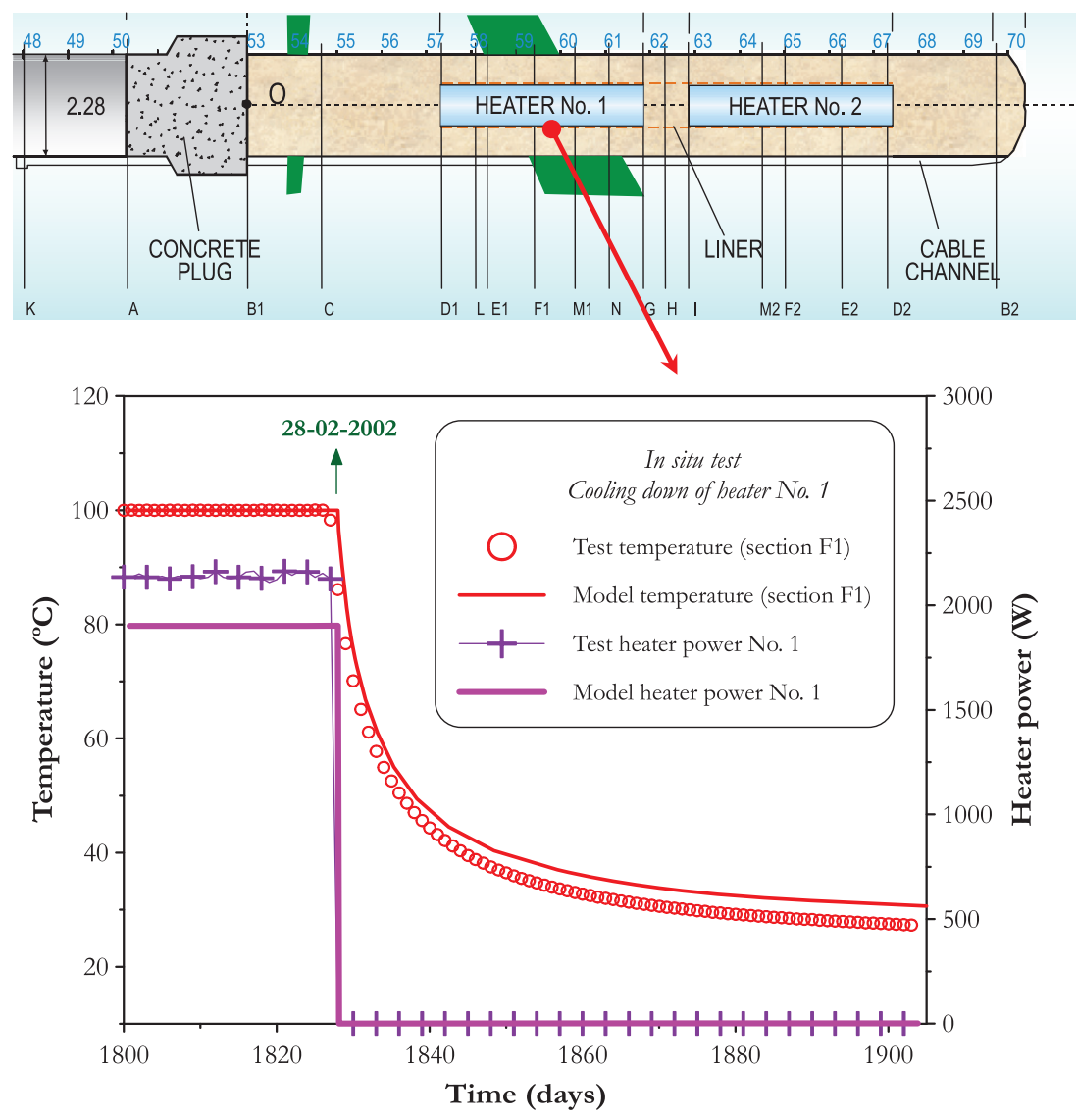

and the preparation of new mesh according to the new geometry after excavation takes place. The excavation procedure described by Potts and Zdravković (1999) has been adapted to the particular conditions used by CODE_BRIGHT to prescribe boundary conditions (Olivella et al. 1996).

Based on the dismantling operation sequence presented in 
Table 2, the following stages have been considered in the numerical analysis:

- Start of plug demolition: 2 April 2002 - day 1860

- End of plug demolition: 28 May 2002 - day 1916

- Start of bentonite excavation: 29 May 2002 - day 1917

- Start of heater\#1 extraction: 19 June 2002 - day 1938

- End of excavation: 19 July 2002 - day 1968

The dates associated with the stages considered in the analysis correspond exactly to those in the field (Barcena et al. 2003). Figure 10 shows schematically the dismantling steps considered in the analysis and the corresponding times.

Figures $11 a$ and $11 b$ present the contours of longitudinal displacement and axial stress computed at different excavation stages. The high swelling capacity of the FEBEX bentonite and the confined conditions of the test induce the development of high swelling pressures in the clay barrier. As expected, axial displacements and reduction of axial stresses in the clay barrier are predicted after concrete plug demolition and subsequent excavation. It can also be observed that the effect of the relaxation of confinement during excavation is quite local and affects zones close to the advance front only.

\section{THM behaviour during cooling down and dismantling}

The partial dismantling was carried out with the fundamental aim of maintaining heater\#2 and all the sensors in the clay barrier and surrounding rock operatives during the whole process. This has provided the opportunity of analyzing the evolution of the main THM variables of the problem during the cooling down of heater\#1 and subsequent excavation. The analysis of the main sensor measurements in both bentonite barrier and rock and their comparison with the model predictions are now discussed. The results are presented for times ranging from day 1750 (i.e., a few days before the cooling of heater\#1) to 1000 days later, when the transient processes induced by the partial dismantling appear to have disappeared. In those sections that were dismantled, the experimental observations are presented until the time at which the sensors were removed from the experiment.

\section{Clay barrier}

In relation to thermal behaviour, the model predicts very well the decrease of temperature at different sections close to heater\#1; see, for example, results in sections $G$ and I presented in Figs. $12 a$ and $12 b$, respectively.

As expected, the disconnection of heater\#1 strongly affected the hydraulic behaviour of the clay barrier in its vicinity. This is mainly because of the key effect of water vapour transfer phenomena on clay barrier hydration. During heating, an increase of the water vapour concentration is expected near the heater. Consequently, water vapour from the internal part of barrier moves outwards driven by the gradient of vapour concentration, which is governed by Fick's law (see Appendix A, eqs. [A20a] and [A20b]). When this water vapour front reaches zones of lower temperature, the water vapour condenses and turns into liquid. The corresponding behaviour on cooling can be observed in Fig. 12c. Just after turning off heater\#1, a rapid increase of the relative humidity was observed in zones close to the heater (i.e., radii $r=0.52 \mathrm{~m}$, Fig. 12c). The lack of water evaporation (and the correspond- ing drying) prevalent there while heater\#1 was switched on is probably the main cause of this behaviour. Furthermore, the progressive increases of relative permeability further out contribute to the hydration in the form of advective liquid fluxes (see Appendix A, eq. [A16]). As hydration progresses, the hydraulic gradient decreases and consequently the saturation rate of the barrier diminishes progressively (see Appendix A, eqs. $[\mathrm{A} 15 a],[\mathrm{A} 15 b]$, and $[\mathrm{A} 15 c])$. The sensors, while they were operative, confirmed the model predictions.

A different behaviour was observed at intermediate radii of the barrier: a moderate reduction of the relative humidity during cooling down was recorded (i.e., $r=0.82 \mathrm{~m}$, Fig. $12 c$ ). This apparent drying is attributed to two main factors. On one hand, vapour transfer (as explained above) stopped when heater\#1 was turned off, and therefore water vapour was no longer arriving in these intermediate zones. On the other, after heater\#1 was turned off there was an increase in the liquid water transfer from the external part to the internal part of the barrier in the form of advective flux (as explained above). These two factors combined to induce a reduction of the availability of liquid water in this zone of the barrier. This drop in relative humidity was detected by the sensors. Finally, the zones near the host rock were not affected by the cooling down of the barrier (i.e., $r=1.10 \mathrm{~m}$, Fig. 12c).

Section $\mathrm{H}$ was moderately affected by the thermal changes induced during the switch-off of heater\#1 due to its relative proximity to this heater. The trends in section $\mathrm{H}$ are qualitatively similar to the ones observed in section E1 (as commented above), but with a less marked effect of the temperature variations (Fig. 12d). The model also describes well the main trends observed in this section, but with a slight underprediction of the relative humidity in the section closer to the heater.

Observing the model results, it can be concluded that overall the model predicts satisfactorily the experimental observations described above. Note that capacitive-type transducers manufactured by Vaisala (Huertas et al. 2006) were used to measure the relative humidity. These types of sensors automatically account for the effect of temperature on relative humidity, so the plotted measurements are related to the actual wetting or drying of the bentonite in the vicinity of the sensor.

\section{Host rock}

As expected, the changes observed in the thermal field depend on the distance to heater\#1. For example, Fig. 13a shows the observed temperature in borehole SF24. Just before switching off heater\#1, the maximum temperature at the sensor nearest the clay barrier (i.e., $r=1.3 \mathrm{~m}$, measured from the axis of the drift) was around $42.5^{\circ} \mathrm{C}$, and a reduction of around $3{ }^{\circ} \mathrm{C}$ was recorded just after heater\#1 was turned off. At a distance of $2.9 \mathrm{~m}$ (from the centre of the drift) the reduction of temperature was around $2.5{ }^{\circ} \mathrm{C}$ and the changes were practically imperceptible at a distance of $9 \mathrm{~m}$. Moving away from the heaters' zone, the temperature around the barrier decreases. For example, Fig. 13b shows that in borehole SB12 (near the concrete plug) the temperature close to the gallery (i.e., $r=1.41 \mathrm{~m}$ ) was around $19^{\circ} \mathrm{C}$ and it reduced by around $5{ }^{\circ} \mathrm{C}$ after heater\#1 disconnection. The model was able to predict very well the temperature evolution in these two quite different zones. 
Fig. 10. Excavation stages considered in the modelling.

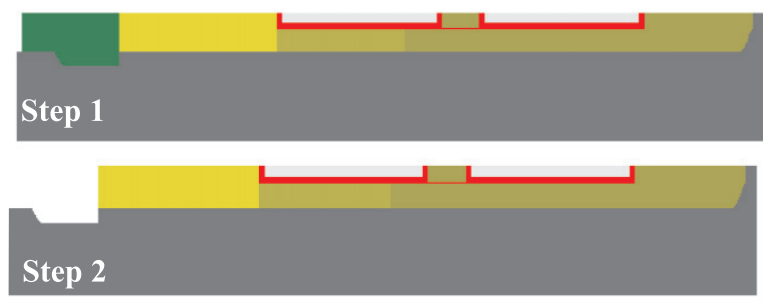

\section{Cooling \\ day 1827}

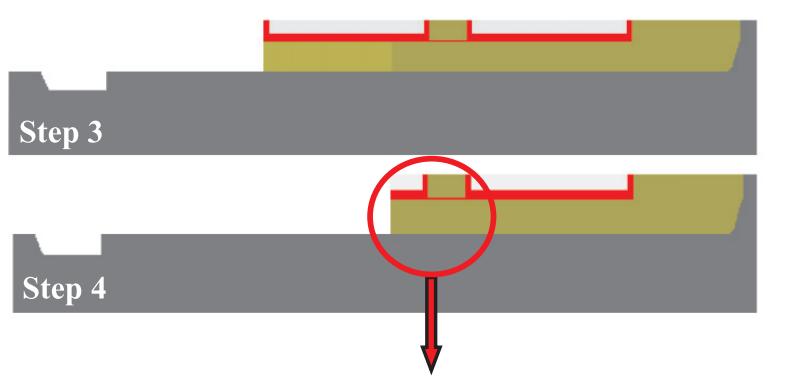

Plug demolition

start day 1860

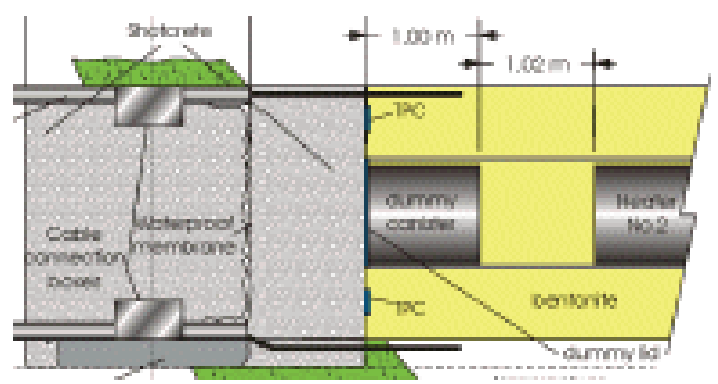

Bentonite excavation start day 1917

Heater No. 1 extraction start day 1938

End of excavation day 1968

Fig. 11. (a) Contours of displacement and (b) of axial stress during excavation (compression is considered positive).

Cooling

day 1827

(a)

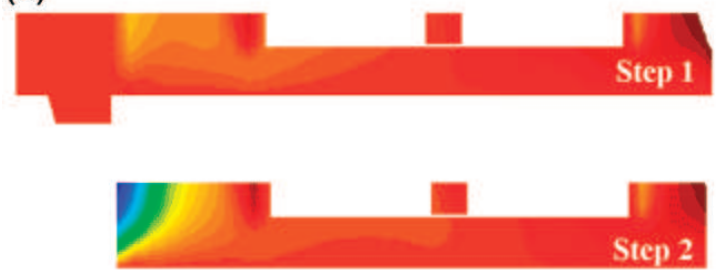

Plug demolition start day 1860

Bentonite excavation start day 1917 (b)
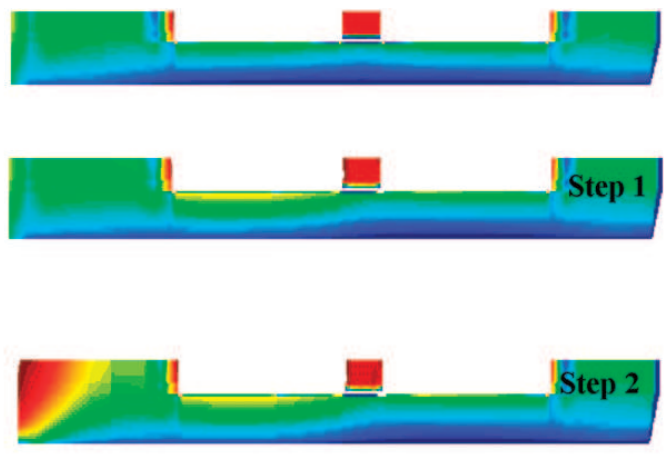

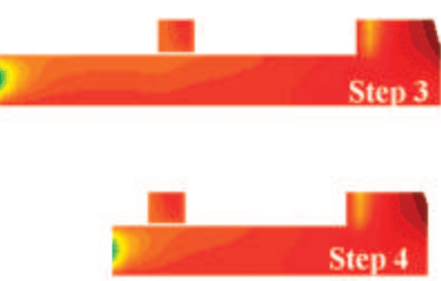

Heater No. 1 extraction start day 1938

End of excavation day 1968

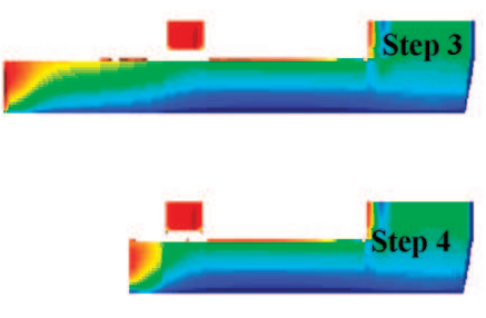

\begin{tabular}{|l|}
\hline Sxx-Stress \\
0 \\
0.55556 \\
1.1111 \\
1.6667 \\
2.2222 \\
2.7778 \\
3.3334 \\
3.8889 \\
4.4445 \\
5 \\
\hline
\end{tabular}

Cooling down and partial dismantling slightly affected the liquid pressure in the host rock. Figure $13 c$ shows the results of a typical piezometer. It can be seen that the model underpredicts the observed change in the liquid pressure. As for the mechanical problem, a noticeable reduction of the normal stresses can be observed (Fig. 13d). This behaviour can be associated with two main factors: $(i)$ the contraction of mate- rials during cooling and (ii) the removal of the clay barrier in heater\#1 zones, with the corresponding release of the bentonite swelling pressure acting against the gallery rock. The fact that the more significant reduction of stresses took place just after switching off heater\#1 indicates that the first factor is the more influential one. As for the stresses in the rock mass, the model underestimates somewhat the strong stress 
Fig. 12. Evolution of temperatures and relative humidity in the clay barrier just before and after switch-off of heater\#1: observed versus computed values of $(a)$ temperature in section $\mathrm{G},(b)$ temperature in section $\mathrm{I},(c)$ relative humidity in section E1, and $(d)$ relative humidity in section $\mathrm{H}$.
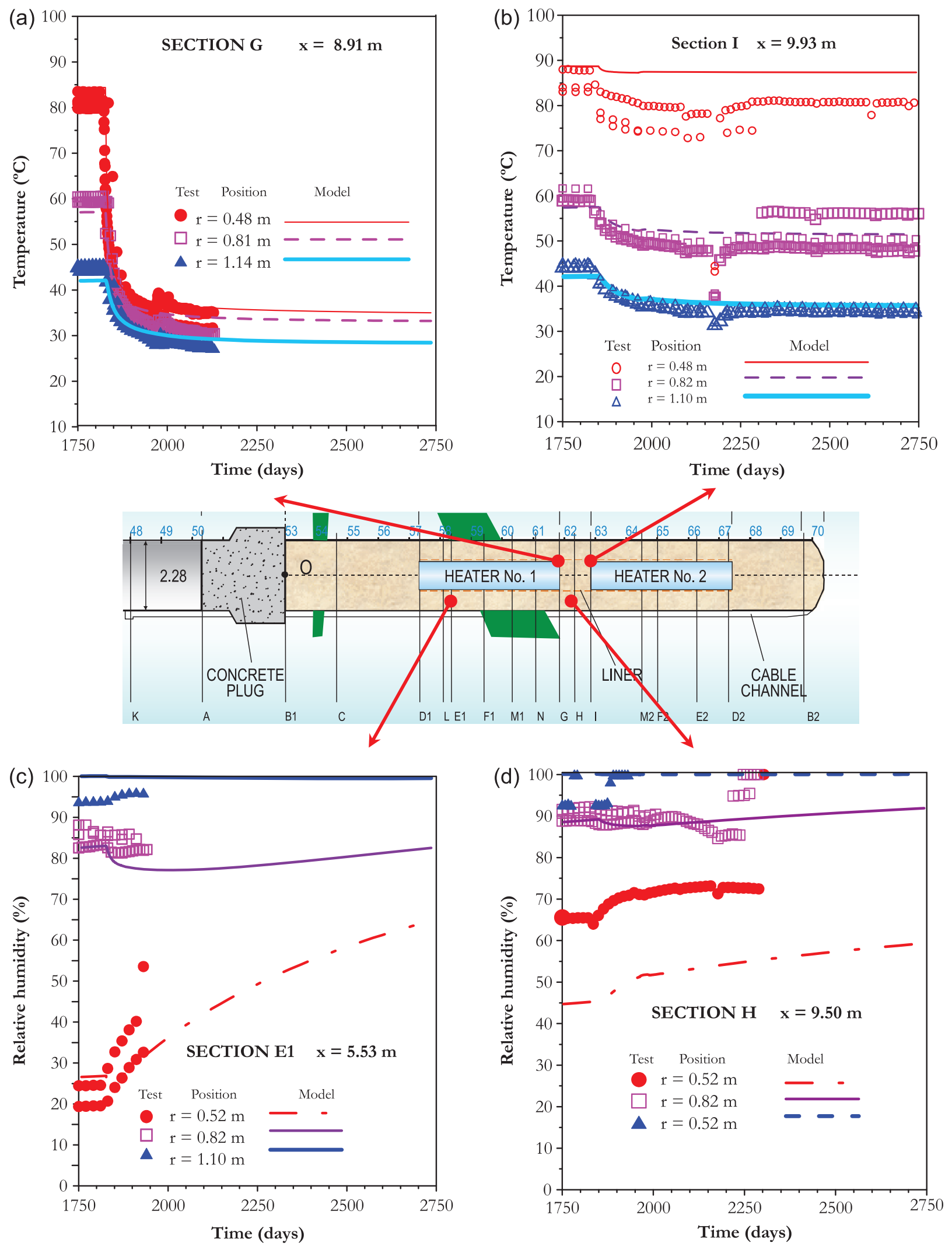
Fig. 13. Evolution of temperatures, liquid pressure, and stresses in the host rock just before and after switch-off of heater\#1. Observed versus computed values of (a) temperature in SF24, $(b)$ temperature in SB12, $(c)$ liquid pressure in SF23, and $(d)$ stress in SG2.
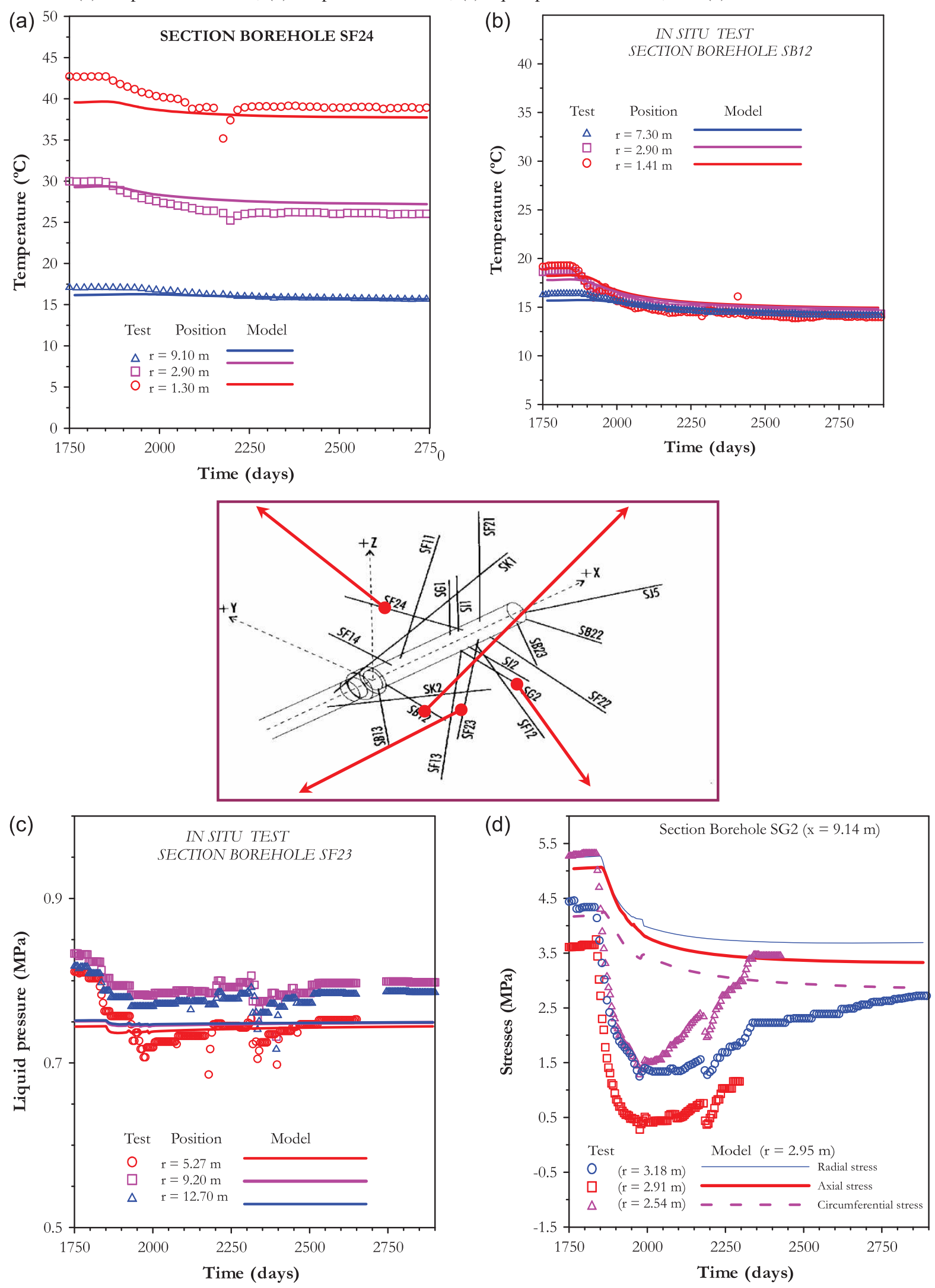
decrease observed just after switching off heater\#1, but it predicts quite well the stress field variations observed afterwards.

\section{Comparison between model predictions and data from new sensors}

This section presents the main results related to the new instrumentation described in the section titled "Final experiment configuration and additional instrumentation". Figures $14 a$ and $14 b$ shows data on the evolution of relative humidity gathered with the new sensors in sections $G$ and I, respectively. The model predictions in the different positions are quite satisfactory in both tendencies and average values, although predictions appear to lie in the lower range of the measured relative humidity values in this part of the barrier. This may be consistent with the presence of the lamprophyre dyke in this zone (see Fig. 1a), which could imply a higher availability of water in this part of the barrier.

Figure $14 c$ presents the results for the total pressure cell located at the contact between the new concrete plug and the clay barrier (section P, Fig. 3a). A quick increase of the stresses in this area is recorded by the pressure cell, while a slow increment is predicted by the model. This difference could be again attributed to the presence of a natural heterogeneity in this part of the barrier (i.e., the lamprophyre) and also to the disturbance induced in that zone by the construction of the new concrete plug. These two factors could lead to a rapid hydration of the bentonite with the corresponding increment of swelling pressure. The model does not contemplate this situation, as a homogeneous porous medium has been assumed in both the rock and clay barrier. A different situation is observed in section F2, where it seems that the new internal sensors (i.e., 0.6 and $0.8 \mathrm{~m}$ ) are not registering stresses reliably yet (Fig. 14d).

A more accurate representation of the problem may be obtained by including the rock heterogeneities observed in the test zone (e.g., the presences of the lamprophyre, fractures), however this will require a more complex three-dimensional modelling of the test.

\section{Long-term predictions}

This section presents the experimental observations registered up to the day 3761; which is approximately 5 years after the partial dismantling, and corresponds to a period of about 10 years of continuous monitoring from the beginning of the test. Model predictions are presented for a period twice the analyzed operation phase (i.e., 20 years). For this paper, this analysis has been identified as "long-term predictions". In the following sections, the results corresponding to the clay barrier are presented first, followed by those related to the host rock. Finally, the long-term hydration of the clay barrier is analyzed for sections with different thermal gradients.

\section{Engineered barrier}

Heater\#2 has been adjusted to maintain at all times the target temperature of $100{ }^{\circ} \mathrm{C}$ at the hottest point of contact between the heater and the bentonite. The model reproduces very well the required jump in the power of heater\#2 (after heater\#1 switch-off) to maintain the target temperature
(Fig. 15a). As already mentioned, the model slightly underpredicts the heater power; nevertheless, the increase of about $5 \%$ in power is estimated correctly. As expected, in sections far from heater\#1, the changes in the thermal field were practically negligible after its cooling down. As shown in Fig. $15 b$, there was only a small decrease of temperature, which is more noticeable in positions at larger radial distances. A tendency towards a slight increase of the power of heater\#2 and temperature can be observed in the long term as hydration progresses. This is related to the increase of thermal conduction with saturation (see Appendix A, eq. [A22]).

The total pressure cells under operation (for the considered period) correspond to sections that were not significantly affected by the dismantling operations. Figures $15 c$ and $15 d$ present the results for two typical sections. The overall model prediction of stresses is quite good, with a maximum stress about 4.5 MPa.

\section{Host rock}

Looking at Figs. $16 a$ to $16 c$, it can be seen that the effect of switching off heater\#1 was quite general and affected the whole near field, inducing a transient thermal period that lasted for around 3 years and was more noticeable in positions closest to heater\#1. The model predicts correctly the measured temperature decay in the granite. As in the clay barrier, long-term predictions show a tendency towards a very slow increase of temperatures in the host rock. The liquid pressures remain practically constant in the long term. As can be seen in Fig. $16 d$, after a pore-water pressure increase during initial heating, quite well captured by the model, practically no changes occurred afterwards.

In terms of mechanical behaviour, the model predicts (qualitatively) well the decay in stresses and radial displacements observed in the surrounding rock after the dismantling operations (Fig. 17). As mentioned in the subsection titled "Host rock" of the section titled "Operational base case analysis", the measured displacements are much lower than the predicted ones (Figs. 17a and 17b). Just after the switch-off of heater\#1, the model predicts a reduction in the radial displacements; with a tendency towards a rather constant values, of around $0.10 \mathrm{~mm}$ near the gallery (i.e., $2.1 \mathrm{~m}$ ), and $0.20 \mathrm{~mm}$ in faraway positions (i.e., 4.1 and $8.1 \mathrm{~m}$ ). As for the experimental observations, a (practically) continuous decrease of those values is measured, leading to negative displacements in some positions. This trend seems unrealistic, especially when compared with the evolution of the stress field (i.e., Figs. $17 c$ and $17 d$ ), suggesting that those sensors are malfunctioning. Also as mentioned in the subsection titled "Host rock" of the section titled "Operational base case analysis", the predicted maximum stresses (i.e., just before cooling) near the gallery (Fig. 17d) are close to the measured ones. The stresses predicted in the long term in this position are between 3 and $4 \mathrm{MPa}$, values that are quite close to the latest measurements. As for positions distant from the barrier (Fig. 17c), the axial stress (i.e., $\sigma_{x x}$ ) is satisfactorily predicted by the model, the circumferential stress is significantly underpredicted, and the sensor measuring radial stress failed after around 3 years of operation. 
Fig. 14. Computed and measured values by the new sensors: $(a)$ relative humidity in section $\mathrm{G},(b)$ relative humidity in section $\mathrm{I}$, (c) stresses in section $\mathrm{P}$, and $(d)$ stresses in section $\mathrm{F} 2$.
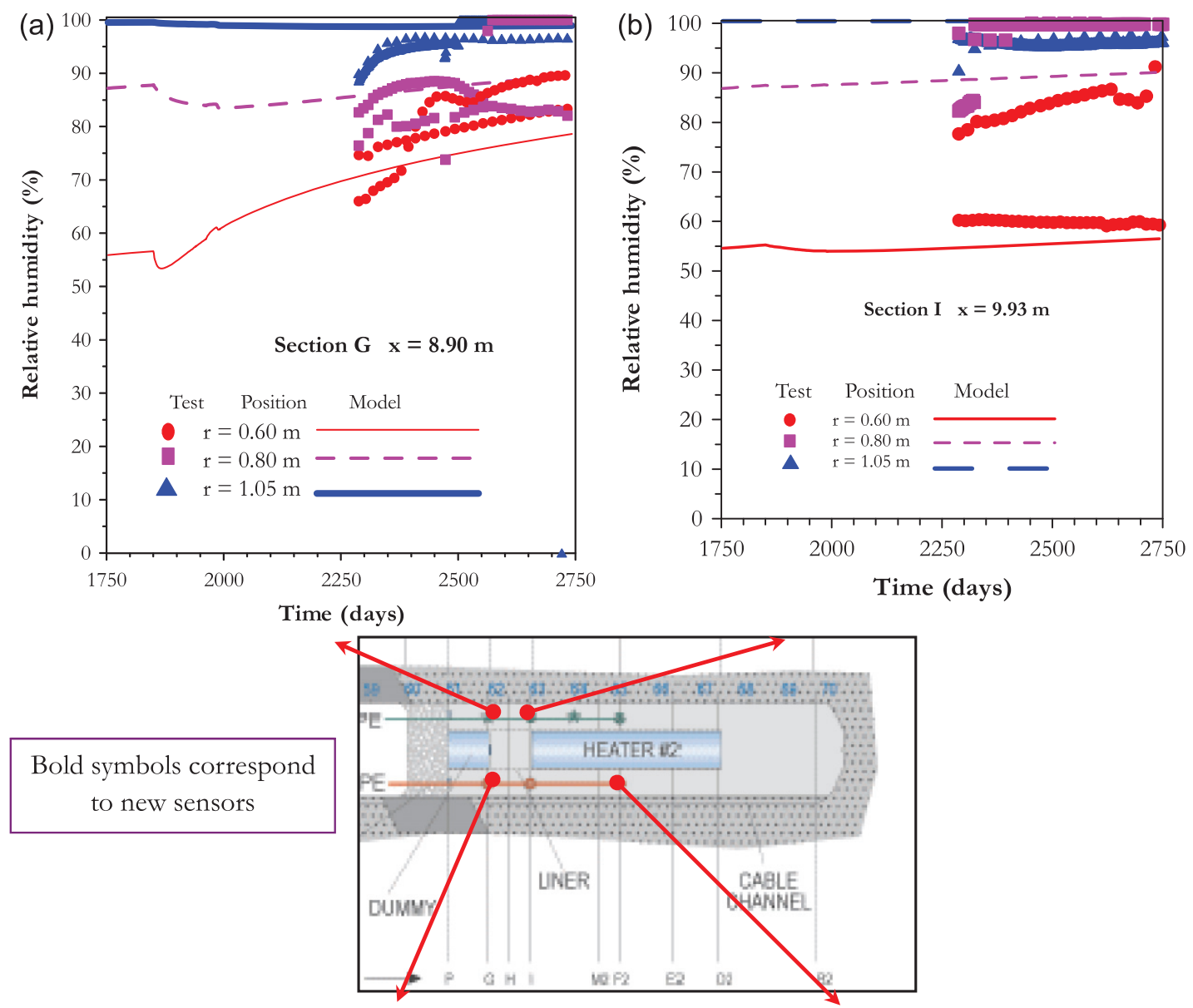

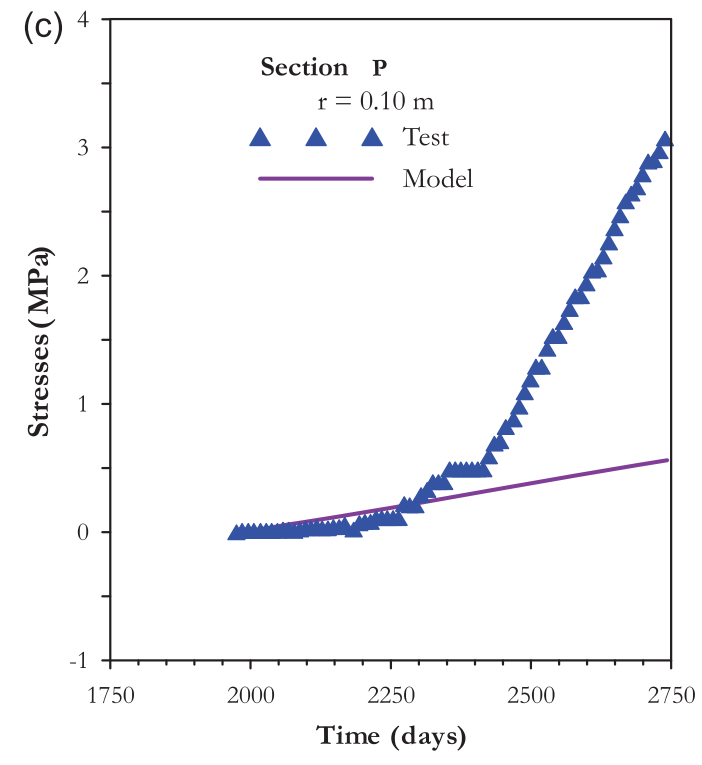

Effect of temperature on long-term hydration of the clay barrier

The effect of temperature on the hydration of clay barriers is of central interest. In many large and small heating tests it has been observed that the hydration time can be much longer than expected. For example, in the mock-up test (the other large heating experiment of the FEBEX project) a ten-

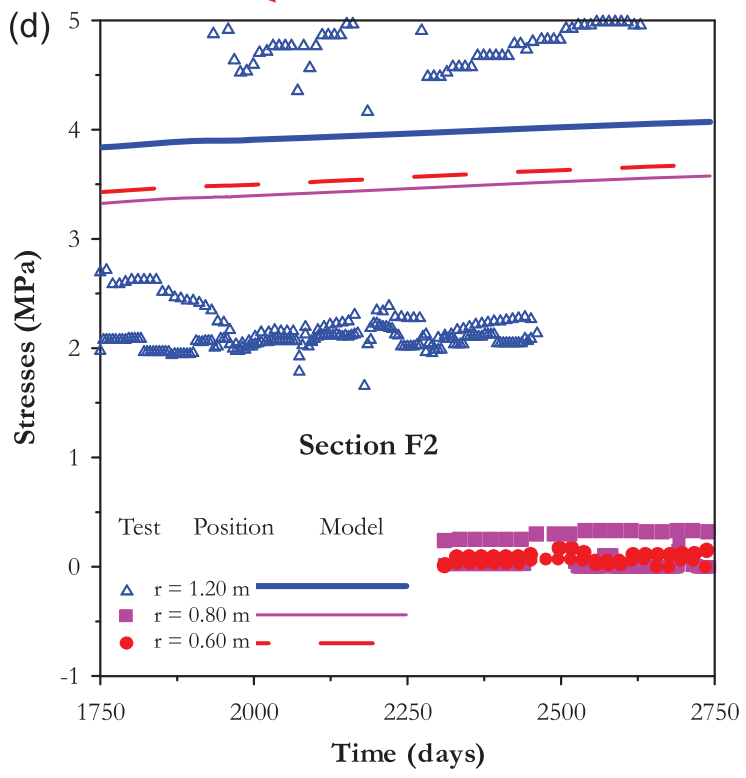

dency towards a very slow hydration has been observed. After 5 years of operation, an important part of the mock-up barrier was still unsaturated, and a general trend towards a very slow saturation was observed (Sánchez et al. 2012). In fact, these observations in the mock-up test motivated the interest in keeping half of the in situ test ongoing, with the explicit aim to explore the long-term hydration of the FEBEX 
Fig. 15. Long term-predictions of thermal and mechnical variables in the clay barrier. Observed versus computed values of $(a)$ power of heater\#2, (b) temperature in section D2, $(c)$ stresses in section E2, and $(d)$ stresses in section B2.
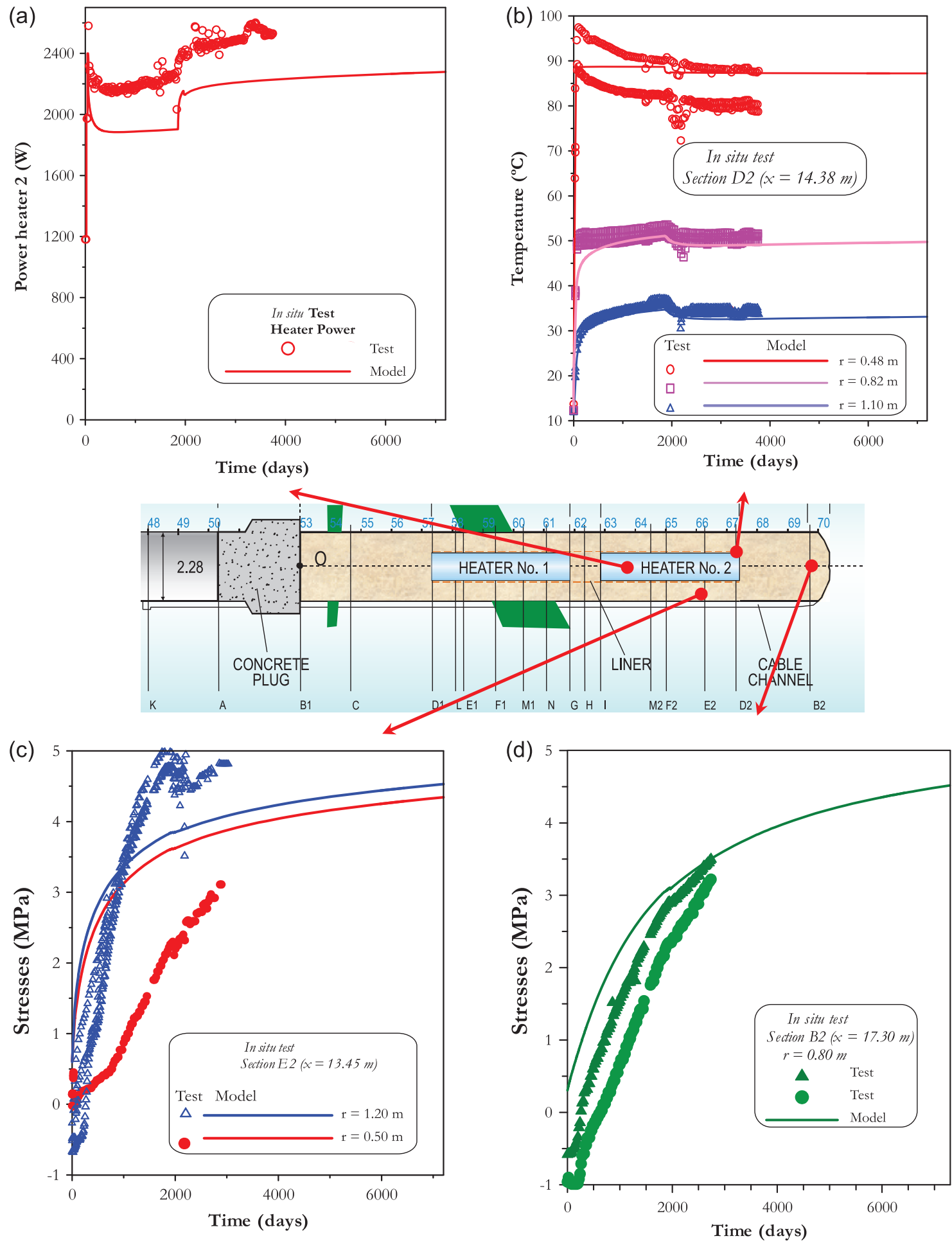

bentonite under natural conditions. Moreover, in the context of the NF-PRO project, slow hydration has also been observed when compacted FEBEX bentonite has been subjected to heating and hydration in cell tests under controlled conditions in the laboratory (e.g., Sánchez et al. 2007). A slow hydration rate has also been observed in other heating

experiments using different clays to build the engineered barriers; for example, the prototype experiment at the Äspö site in Sweden. Furthermore, unexpected quite low saturation of a clay barrier was also observed in a large-scale isothermal test subjected to natural hydration in Canada (Dixon et al. 2002; Thomas et al. 2003). This is an unanticipated result that 
Fig. 16. Long-term predictions of thermal and hydraulic variables in the host rock. Observed versus computed values of $(a)$ temperature in section SF24; $(b)$ temperature in section SF22; $(c)$ temperature in section SB12; $(d)$ liquid pressure SF23.
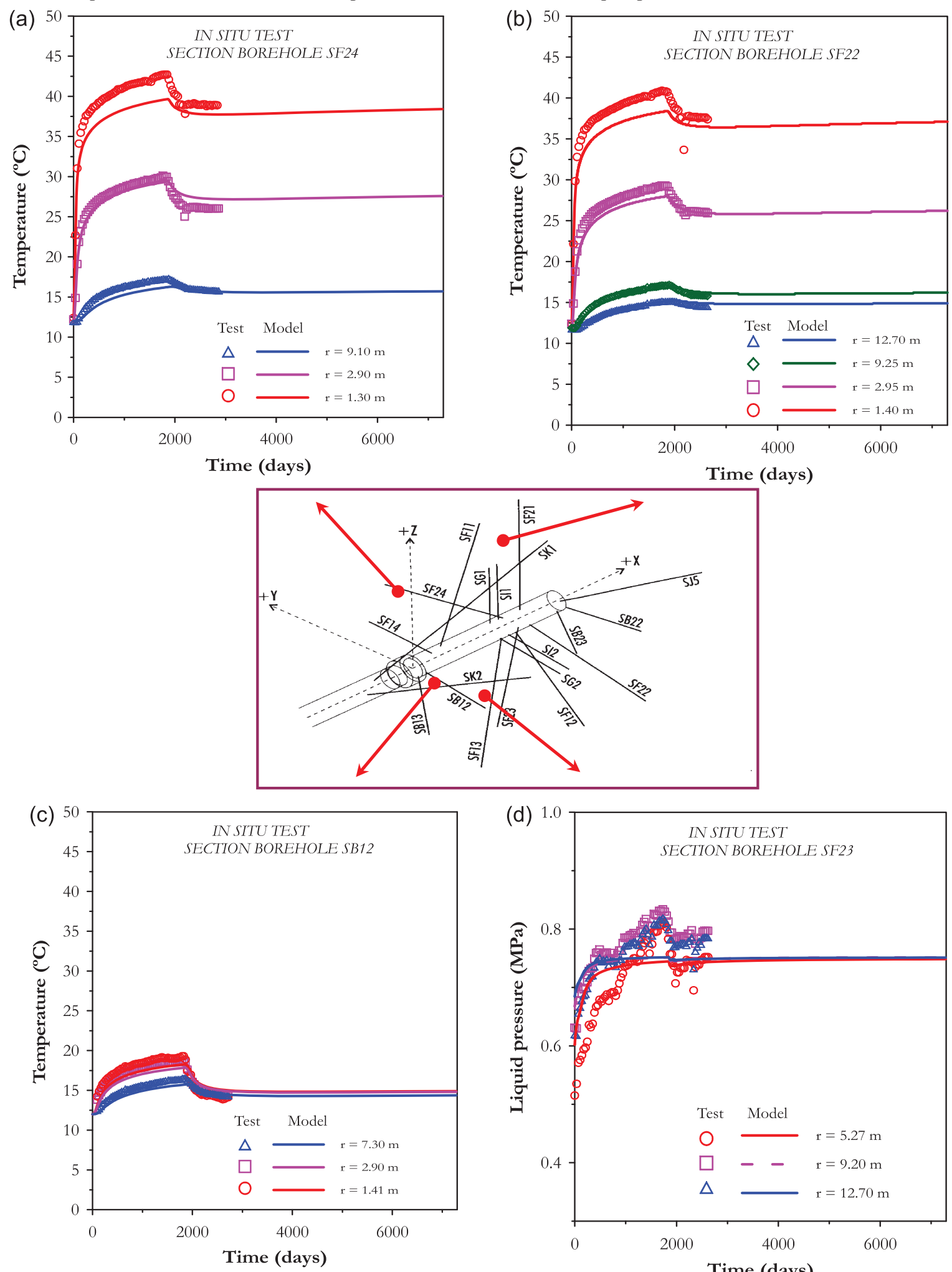

could imply that a clay barrier subjected to natural hydration even under isothermal conditions could remain unsaturated for very long periods.

In this context, the switching off of heater\#1 and the new

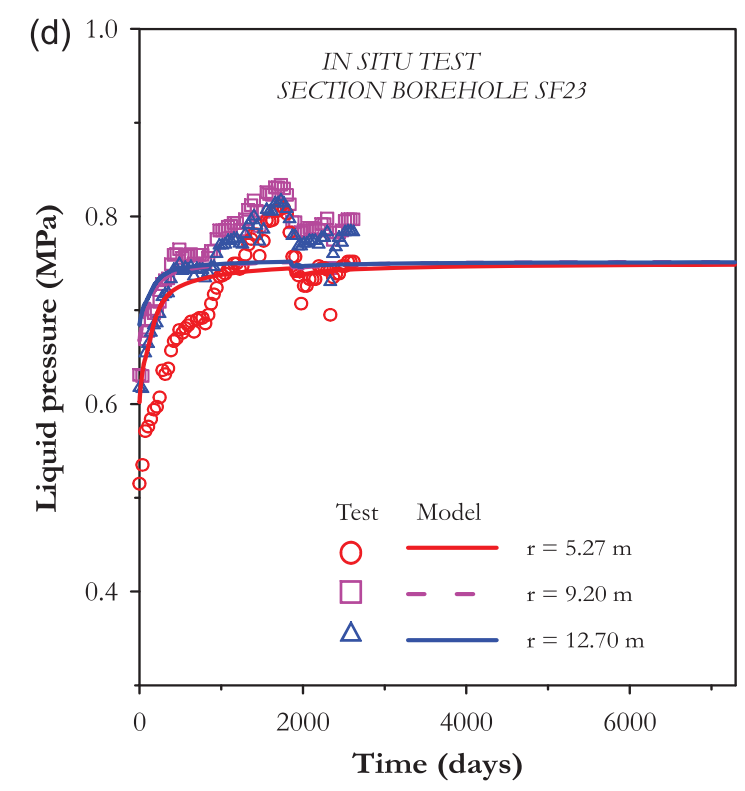

sensors installed in the barrier have provided an excellent opportunity to analyze the influence of the cooling down on the kinetics of hydration of the clay barrier. For example, looking at section E1 in Fig. $6 c$, it is evident that before the heater\#1 
Fig. 17. Long-term predictions of mechanical variables in the host rock. Observed versus computed values of $(a)$ radial displacement in section SI2; (b) radial displacement in section SI1; stresses in sections $(c)$ SG1 and $(d)$ SG2.
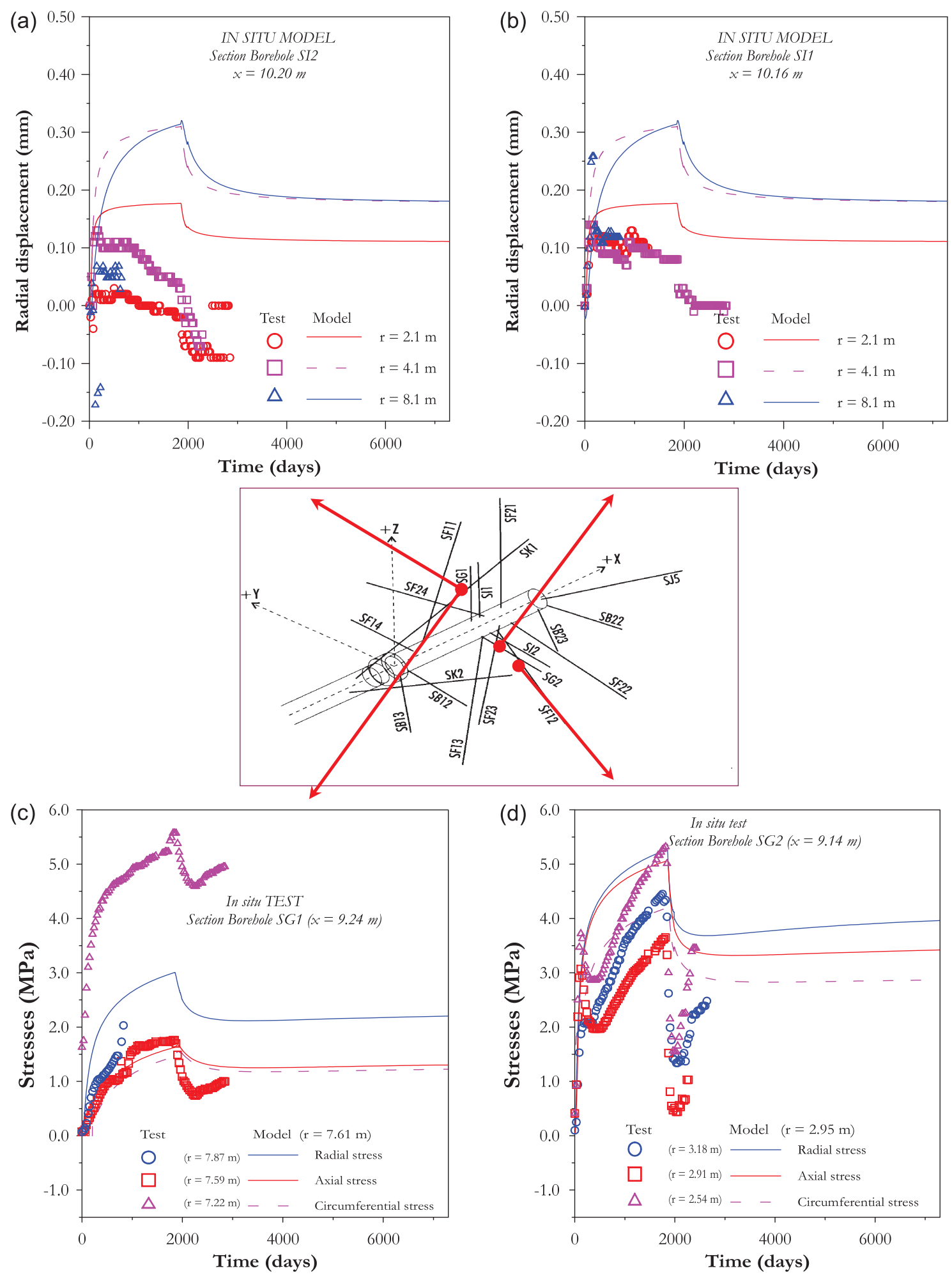

switch-off there was a tendency towards a very low hydration in sections close to the heater. After the switch-off of heater\#1, a fast increase of the relative humidity is predicted by the model for this zone of the barrier (Fig. 12c). The experimental data during the barrier cooling down confirmed the

fast hydration predicted by the model, although these records were available only for a relatively short period of time (due to the dismantling operations carried out in this section). Fortunately, the new sensors installed in section $G$ (which is also in the heater\#1 zone) have provided the op- 
Fig. 18. Long-term predictions of relative humidity in the clay barrier. Observed versus computed values in sections (a) E1, (b) G, (c) H, and (d) F2.
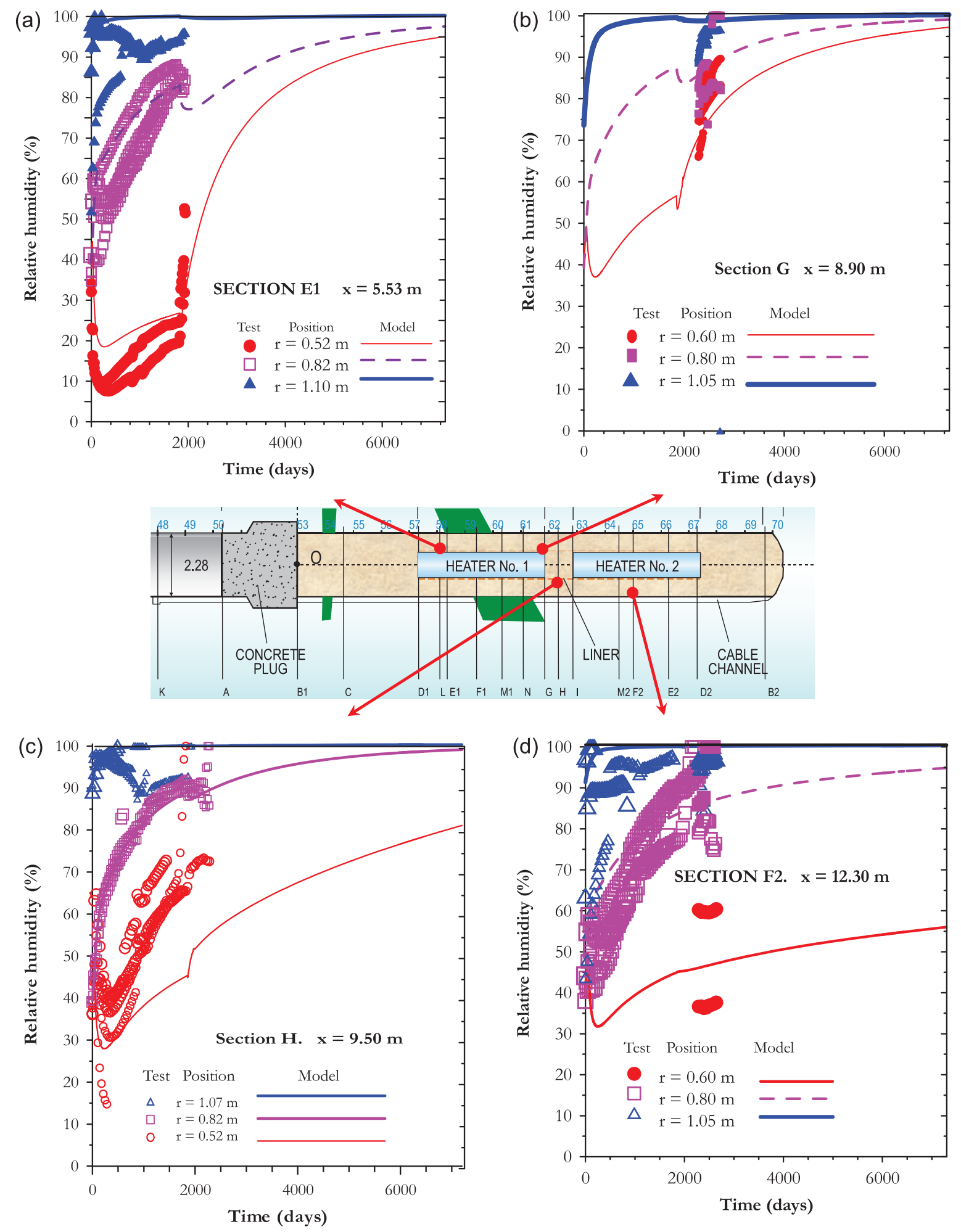

portunity to confirm the model predictions for a much longer period (Fig. 14a). It is apparent that the behaviour of sections $\mathrm{E} 1$ and $\mathrm{G}$ are not exactly the same, because the thermal gradient is different (section $G$ is closer to heater\#2), but they follow a similar trend. Figures $18 a$ and
$18 b$ present the long-term predictions for the two sections discussed above (E1 and G). The model predicts that after 20 years of testing, a (practically) full saturation will be attained in sections such as E1 under practically nil thermal gradients (as can be observed in Fig. 8b). Figures $18 c$ and 
$18 d$ show that as the thermal gradient of the section increases (see Fig. 8b), the rate of hydration reduces significantly. The new sensors installed in section F2 at a radial distance of $0.60 \mathrm{~m}$ are recording values of relative humidity between $60 \%$ and $30 \%$, which is a quite wide range. Model predictions are just in-between the measured values.

Considering that a very slow cooling down of the barrier due to the radioactive decay is expected in the long term, the analyses presented here are quite relevant to the behaviour of the barrier under these conditions.

\section{Conclusions}

One of the main objectives of the modelling related to nuclear waste disposal is to achieve a better understanding of the thermal-hydraulic-mechanical processes expected in the repository near-field and to provide a capability for quantitative predictions of these processes by numerical analyses. These two goals have been satisfactorily accomplished in the analyses presented in this paper. The cooling and partial dismantling of the in situ test have offered an excellent opportunity to explore the THM behaviour under conditions that are different from those generally studied to date, but are quite relevant to the performance of repositories. The availability of measurements of the main THM variables from sensors strategically located in the clay barrier and surrounding rock and the corresponding interpretation in light of the adopted coupled formulation have been very useful to learn about the main THM phenomena that took place during the transient period induced by the partial dismantling operations. The overall performance of the computer code has resulted in quite satisfactory predictions in both qualitative and quantitative terms. Evidently, the proposed approach presents some limitations for fully capturing the observed behaviour, particularly in terms of the stress field. The mechanical behaviour of the clay may be improved by using a more advanced model for expansive clays (e.g., Sánchez et al. 2005). A simple linear elastic model was adopted for the granite; a better representation of its behaviour (especially at advanced stages) may be achieved by using a more sophisticated constitutive model for representing the rock behaviour. In any case, it can be concluded that the coupled formulation and computer code used in the analysis are indeed capable of simulating realistically the THM behaviour in the near field.

The paper also presents the model predictions for the main THM variables for a period of 20 years (i.e., about twice the time of experimental observations presented in this paper). Particularly interesting are the predictions related to the hydration time of the clay barrier, a key issue in analysis related to nuclear was disposal due to its impact on other relevant processes such as chemical processes in the barrier and canister corrosion. The model predictions have been presented for four sections affected differently by the cooling down of the barrier. It has been observed that the thermal field has a significant influence on the hydration time. The model predicts that after 20 years of operations, the barrier with a very low hydraulic gradient will be fully saturated. The model also shows that a quite slow hydration of the clay is expected in zones subjected to thermal gradients. Existing and new sensors (installed after the partial dismantling) have confirmed the model trends during the barrier cooling-down period.

\section{Acknowledgements}

The authors gratefully acknowledge the financial and technical support of ENRESA and the Commission of the European Union. We also thank AITEMIN and CIEMAT for their technical assistance and useful discussions. Finally, we would like to thank the reviewers of this paper for their comments and suggestions.

\section{References}

Åkesson, M., Jacinto, A.C., Gatabin, C., Sánchez, M., and Ledesma, A. 2009. Bentonite THM behaviour at high temperatures: experimental and numerical analysis. Géotechnique, 59(4): 307318. doi:10.1680/geot.2009.59.4.307.

Alonso, E.E., and Alcoverro, J. 2005. DECOVALEX III project: modelling of FEBEX in-situ test, task 1. Final Report. Statens Kärnkraftinspektion Editor. SKI, Sweden.

Barcena, I., Fuentes-Castillana, J., and Garcia-Siñeriz, J. 2003. Dismantling of heater $\mathrm{N}^{\circ} 1$ at the FEBEX in-situ test. Descriptions of operations. Report: 70-AIT-L-6-03.

Chen, G., and Ledesma, A. 2009. Coupled thermohydromechanical modeling of the full-scale in situ test prototype repository. Journal of Geotechnical and Geoenvironmental Engineering, 135(1): 121132. doi:10.1061/(ASCE)1090-0241(2009)135:1(121).

Dixon, D., Chandler, N., Graham, J., and Gray, M.N. 2002. Two large-scale sealing tests conducted at Atomic Energy of Canada's underground research laboratory: the buffer-container experiment and the isothermal test. Canadian Geotechnical Journal, 39(3): 503-518. doi:10.1139/t02-012.

Gens, A. 2010. Soil-environment interactions in geotechnical engineering. Géotechnique, 60(1): 3-74. doi:10.1680/geot.9.P.109.

Gens, A., Garcia-Molina, A., Olivella, S., Alonso, E.E., and Huertas, F. 1998. Analysis of a full scale in-situ test simulating repository conditions. International Journal for Numerical and Analytical Methods in Geomechanics, 22(7): 515-548. doi:10.1002/(SICI) 1096-9853(199807)22:7<515::AID-NAG926>3.0.CO;2-8.

Gens, A., Sánchez, M., Guimarães, L., Alonso, E.E., Lloret, A., Olivella, S., Villar, M.V., and Huertas, F. 2009. A full scale in situ heating test for high level nuclear waste disposal. Observations, analysis and interpretation. Géotechnique, 59(4): 377-399. doi:10. 1680/geot.2009.59.4.377.

Huertas, F., Farina, P., Farias, J., Garcia-Sineriz, J.L., Villar, M.V., Fernandez, A.M., et al. 2006. Full-scale engineered barrier experiment. ENRESA, Madrid. Updated final report, technical publication 05-0/2006.

Hughes, T.J. 1980. Generalization of selective integration procedures to anisotropic and nonlinear media. International Journal for Numerical and Analytical Methods in Engineering, 15(9): 14131418. doi:10.1002/nme.1620150914.

Lloret, A., Villar, M.V., Sánchez, M., Gens, A., Pintado, X., and Alonso, E.E. 2003. Mechanical behaviour of heavily compacted bentonite under high suction changes. Géotechnique, 53(1): 27 40. doi:10.1680/geot.2003.53.1.27.

Martín, P.L., and Barcala, J.M. 2005. Large scale buffer material test: Mock-up experiment at CIEMAT. Engineering Geology, 81(3): 298-316. doi:10.1016/j.enggeo.2005.06.013.

Olivella, S., Carrera, J., Gens, A., and Alonso, E.E. 1994. Nonisothermal multiphase flow of brine and gas through saline media. Transport in Porous Media, 15(3): 271-293. doi:10.1007/ BF00613282.

Olivella, S., Gens, A., Carrera, J., and Alonso, E.E. 1996. Numerical formulation for a simulator (CODE-BRIGHT) for the coupled analysis of saline media. Engineering Computations, 13(7): 87112. doi:10.1108/02644409610151575. 
Potts, D., and Zdravković, L. 1999. Finite element analysis in geotechnical engineering: theory. Thomas Telford Publishing.

Pusch, R., and Karnland, O. 1996. Physico/chemical stability of smectite clays. Engineering Geology, 41(1-4): 73-85. doi:10. 1016/0013-7952(95)00027-5.

Rutqvist, J., Barr, D., Datta, R., Gens, A., Millard, M., Olivella, S., Tsang, C.F., and Tsang, Y. 2005. Coupled thermal-hydrological-mechanical analysis of the Yucca Mountain Drift Scale Test—comparison of field measurements to predictions of four different numerical models. International Journal of Rock Mechanics and Mining Sciences, 42(5-6): 680-697. doi:10.1016/j.ijrmms.2005.03.008.

Sánchez, M., Gens, A., Guimarães, L., and Olivella, S. 2005. A double structure generalized plasticity model for expansive materials. International Journal for Numerical and Analytical Methods in Geomechanics, 29(8): 751-787. doi:10.1002/nag.434.

Sánchez, M., Villar, M.V., Lloret, A., and Gens, A. 2007. Analysis of the expansive clay hydration under low hydraulic gradient. In Experimental unsaturated soil mechanics. Springer Proceedings in Physics. Springer, Berlin. Vol. 112, pp. 309-318.

Sánchez, M., Gens, A., Guimarães, L., and Olivella, S. 2008. Implementation algorithm of a generalized plasticity model for swelling clays. Computers and Geotechnics, 35(6): 860-871. doi:10.1016/j.compgeo.2008.08.004.

Sánchez, M., Gens, A., and Olivella, S. 2012. THM analysis of a large scale heating test incorporating material fabric changes. International Journal for Numerical and Analytical Methods in Geomechanics, 36(4): 391-421. doi:10.1002/nag.1011.

Siemens, G., and Blatz, J. 2009. Evaluation of the influence of boundary confinement on the behaviour of unsaturated swelling clay soils. Canadian Geotechnical Journal, 46(3): 339-356. doi:10. 1139/T08-125.

Svemar, C., and Push, R. 2002. Äspö Hard Rock Laboratory. International Progress Report, 2002. IPR-00-IPR-30. SKB.

Thomas, H.R., and He, Y. 1995. An analysis of coupled heat, moisture and air transfer in a deformable unsaturated soil. Géotechnique, 45: 667-689.

Thomas, H., Cleall, P., Chandler, N., Dixon, D., and Mitchell, H. 2003. Water infiltration into a large-scale in-situ experiment in an underground research laboratory. Géotechnique, 53(2): 207-224. doi:10.1680/geot.2003.53.2.207.

Thomas, H.R., Cleall, P.J., Dixon, D., and Mitchell, H.P. 2009. The coupled thermal-hydraulic-mechanical behaviour of a large-scale in situ heating experiment. Géotechnique, 59(4): 401-413. doi:10. 1680/geot.2009.59.4.401.

van Genuchten, R. 1978. Calculating the unsaturated hydraulic permeability conductivity with a new closed-form analytical model. Water Resources Research, 37(11): 21-28.

Villar, M.V. 2002. Thermo-hydro-mechanical characterisation of a bentonite from Cabo de Gata: a study applied to the use of bentonite as sealing material in high-level radioactive waste repositories. ENRESA, Madrid. Technical Publication 01/2002.

Volckaert, G., Dereeper, B., Put, M., Ortiz, L., Gens, A., Vaunat, J., et al. 2000. A large-scale in situ demonstration test for repository sealing in an argillaceous host rock. Reseal Phase I Project Report 2000. European Commission, Brussels.

\section{Appendix A. Mathematical formulation}

\section{Balance equations}

Mass balance equations were established following the compositional approach, which consists of balancing the species rather than the phases. The notation used herein is presented in Table 1.
Water is present in liquid and gas phases. The total mass balance of water is expressed as (Olivella et al. 1994)

$[\mathrm{A} 1] \quad \frac{\partial}{\partial t}\left(\theta_{1}^{\mathrm{w}} S_{\mathrm{l}} n+\theta_{\mathrm{g}}^{\mathrm{w}} S_{\mathrm{g}} n\right)+\nabla \cdot\left(\boldsymbol{j}_{1}^{\mathrm{w}}+\boldsymbol{j}_{\mathrm{g}}^{\mathrm{w}}\right)=f^{\mathrm{w}}$

The main variable associated with this equation is the liquid pressure $\left(P_{1}\right)$. A similar equation can be written for the mass balance of air (Olivella et al. 1994), however this equation has not been used in thess analyses as a constant gas pressure has been assumed (Gens et al. 2009). Thermal equilibrium between phases has been assumed; consequently only one equation is required to establish energy balance. The total internal energy per unit volume of porous media is obtained by adding the internal energy of each phase corresponding to each medium. Applying the balance equation to this quantity, the following equation is obtained:

$$
\begin{aligned}
\frac{\partial}{\partial t}\left[E_{\mathrm{s}} \rho_{\mathrm{s}}(1-n)+E_{1} \rho_{1} S_{\mathrm{l}} n+E_{\mathrm{g}} \rho_{\mathrm{g}} S_{\mathrm{g}} n\right] & \\
& +\nabla \cdot\left(\boldsymbol{i}_{\mathrm{c}}+\boldsymbol{j}_{\mathrm{Es}}+\boldsymbol{j}_{\mathrm{El}}+\boldsymbol{j}_{\mathrm{Eg}}\right)=f^{\mathrm{E}}
\end{aligned}
$$

The temperature $(T)$ is the main variable associated with this equation. The balance of momentum for the porous medium reduces to the equilibrium equation in total stresses

$$
\text { [A3] } \nabla \cdot \boldsymbol{\sigma}+\boldsymbol{b}=0
$$

Through an adequate constitutive model (presented in the next section), the equilibrium equation is transformed into a form expressed in terms of solid velocities and fluid pressures. The assumption of small strain rate is also made. The displacement field $(\boldsymbol{u})$ is the main variable associated with this equation. In addition, the mass balance of solid is established for the whole porous medium and it is used to update the porosity (Olivella et al. 1996).

\section{Constitutive equations and equilibrium restrictions}

Laboratory tests carried out in the context of the FEBEX project (Gens et al. 2009) have been used to determine independently the different parameters of the constitutive models used in the numerical simulation of the in situ test. The main constitutive laws and the corresponding adopted parameters are presented in the following sections.

\section{Mechanical constitutive model}

The Barcelona Basic Model (BBM) has been adopted to model the mechanical behaviour of the clay barrier (Alonso et al. 1990). The model is formulated in terms of the three stress invariants $(p ; J ; \theta)$; suction, and temperature. The descriptions of the stress invariants are provided in the section titled "Stress invariants". The trace of the yield function on the isotropic $p-s$ plane is called the loading-collapse (LC) yield curve, because it represents the locus of activation of irreversible deformations due to loading increments or wetting (collapse compression). The position of the LC curve is given by the value of the hardening variable $p_{0}^{*}$. The BBM yield surface $(F)$ is then expressed as

$$
F=3 J^{2}-\left[\frac{g(\theta)}{g\left(-30^{\circ}\right)}\right]^{2} M^{2}\left(p+p_{\mathrm{s}}\right)\left(p_{0}-p\right)=0
$$


When yielding takes place the increment of plastic deformations is evaluated through:

$$
\text { [A5 }] \quad \dot{\varepsilon}^{\mathrm{p}}=\lambda \frac{\partial G}{\partial \sigma}
$$

where $G$ is the plastic potential as follows:

[A6] $\quad G=\alpha_{G} 3 J^{2}-\left[\frac{g(\theta)}{g\left(-30^{\circ}\right)}\right]^{2} M^{2}\left(p+p_{\mathrm{s}}\right)\left(p_{0}-p\right)=0$

where $\alpha_{G}$ is the material parameter that controls the degree of nonassociativeness, determined according to (Alonso et al. 1990).

The hardening law is expressed as a rate relation between the volumetric plastic strain and the saturated isotropic preconsolidation stress " $p_{0}^{*}$ ", according to

$[\mathrm{A} 7] \quad \frac{\dot{p}_{0}^{*}}{p_{0}^{*}}=\frac{(1+e)}{\left(\lambda_{(0)}-\kappa\right)} \dot{\varepsilon}_{\mathrm{v}}^{\mathrm{p}}$

The dependence of the tensile strength on suction and temperature is given by (Gens 1995)

$$
\text { [A8] } \quad p_{\mathrm{s}}=k s e^{-\rho \Delta T}
$$

The dependence of $p_{0}$ on suction is given by

$$
\begin{aligned}
& {[\mathrm{A} 9 a] \quad p_{0}=p_{\mathrm{c}}\left(\frac{p_{0 T}^{*}}{p_{\mathrm{c}}}\right)^{\left(\lambda_{(0)}-\kappa\right) /\left(\lambda_{(\mathrm{s})}-\kappa\right)}} \\
& {[\mathrm{A} 9 b] \quad p_{0 T}^{*}=p_{0}^{*}+2\left(\alpha_{1} \Delta T+\alpha_{3} \Delta T|\Delta T|\right)}
\end{aligned}
$$

The compressibility parameter for changes in net mean stress for virgin states of the soil $\left(\lambda_{(\mathrm{s})}\right)$ depends on suction according to

$[\mathrm{A} 10] \quad \lambda_{(\mathrm{s})}=\lambda_{(0)}\left[r_{\mathrm{m}}+\left(1-r_{\mathrm{m}}\right) \exp (-\zeta s)\right]$

The bulk modulus $(K)$ for changes in mean stress is evaluated with the following law:

$$
\text { [A11] } K=\frac{(1+e)}{\kappa} p
$$

The bulk modulus for changes in suction is computed according to the following law:

$$
K_{\mathrm{s}}=\frac{(1+e)\left(s+p_{\mathrm{atm}}\right)}{\kappa_{\mathrm{s}}}
$$

The bulk modulus for changes in temperature is computed by the following law:

$$
\text { [A13] } \quad K_{T}=\frac{1}{\left(\alpha_{0}+\alpha_{2} \Delta T\right)}
$$

where $\alpha_{0}$ and $\alpha_{2}$ are parameters related to the elastic thermal strain.

Due to the high compaction that the bentonite blocks have been subjected to, the description of the behaviour of the material inside the yield surface is particularly important. The variation of stress-stiffness with suction and the variation of swelling potential with stress and suction have been considered. The resulting elastic model is the following:

$[\mathrm{A} 14 a] \quad \dot{\varepsilon}_{\mathrm{v}}^{\mathrm{e}}=\frac{\kappa}{(1+e) \frac{\dot{p}}{p}}+\frac{\kappa_{\mathrm{s}}}{(1+e)} \frac{\dot{s}}{(s+0.1)}$ $+\left(\alpha_{0}+\alpha_{2} \Delta T\right) \dot{T}$

$[\mathrm{A} 14 b] \quad \dot{\varepsilon}_{\mathrm{s}}^{\mathrm{e}}=\frac{\dot{J}}{G_{\mathrm{t}}}$

where (Technical University of Catalonia 2011)

$[\mathrm{A} 15 a] \quad \kappa=\kappa_{i}\left(1+\alpha_{\mathrm{s}} s\right)$

$[\mathrm{A} 15 b] \quad \kappa_{\mathrm{s}}=\kappa_{\mathrm{s} 0}\left(1+\alpha_{\mathrm{sp}} \ln p / p_{\mathrm{ref}}\right)$

$[\mathrm{A} 15 c] \quad G_{\mathrm{t}}=\frac{3(1-2 \mu) K}{2(1+\mu)}$

The model parameters were determined from the experimental laboratory campaign carried out during the FEBEX project (Gens et al. 2009). As an example, Fig. $4 a$ shows the computed results of two swelling pressure tests according to Lloret et al. (2003).

The thermomechanical behaviour of the rock and concrete has been described using a linear elastic model in terms of a bulk modulus $(K)$ and shear modulus $\left(G_{t}\right)$, and a coefficient of linear expansion, $\alpha_{0}$. The main model parameters for the clay barrier, concrete and granite, are presented in Table 3.

\section{Constitutive models related to the hydraulic behaviour}

The models introduced below have been adopted to describe the behaviour of the porous materials (i.e., clay barrier, granite, and concrete). Advective fluxes are computed using a generalized Darcy's law, expressed as

$$
\boldsymbol{q}_{\alpha}=-\boldsymbol{K}_{\alpha}\left(\nabla P_{\alpha}-\rho_{\alpha} g\right) \quad \alpha=1, \mathrm{~g}
$$

The permeability tensor is evaluated according to

$$
\boldsymbol{K}_{\alpha}=\boldsymbol{k} \frac{k_{r \alpha}}{\mu_{\alpha}} \quad \alpha=1, \mathrm{~g}
$$

The dependence of intrinsic permeability on porosity has been based on Kozeny's law

$$
\boldsymbol{k}=k_{0} \frac{n^{3}}{(1-n)^{2}} \frac{\left(1-n_{0}\right)^{2}}{n_{0}^{3}} \boldsymbol{I}
$$

Permeability tests performed on saturated samples have been used to adopt the reference values: $k_{0}=1.9 \times 10^{-21} \mathrm{~m}^{2}$ for a porosity of 0.40 (Fig. $4 b$ ). The well-known power law has been adopted to describe the dependence of liquid permeability on degree of saturation

[A19] $\quad k_{\mathrm{rl}}=S_{1}^{n_{\mathrm{s}}}$

A value of $n_{\mathrm{s}}=3$ has been determined from back-calculating hydration tests on FEBEX bentonite. The water-retention curve relates the degree of saturation of the material with 
suction. The law adopted is based on the van Genuchten (1978) model, as follows:

$$
\begin{aligned}
& {\left[\text { A20a } \quad S_{1}=\left[1+\left(\frac{s}{P_{0}}\right)^{1 /\left(1-\lambda_{0}\right)}\right]^{-\lambda_{0}} f_{\mathrm{d}}\right.} \\
& {[\text { A20 } b] \quad f_{\mathrm{d}}=\left(1-\frac{s}{P_{\mathrm{d}}}\right)^{\lambda_{\mathrm{d}}}}
\end{aligned}
$$

Figure $4 c$ presents the results of tests carried out at conditions of constant volume on FEBEX bentonite, together with the adopted relationship. Model parameters are: $P_{0}=$ $20 \mathrm{MPa}, \lambda_{0}=0.18, P_{\mathrm{d}}=1100 \mathrm{MPa}$, and $\lambda_{\mathrm{d}}=1.10$.

Nonadvective fluxes of species inside the fluid phases are computed through Fick's law, which expresses them in terms of gradients of mass fraction of species through a hydrodynamic dispersion tensor that includes both molecular diffusion and mechanical dispersion

$$
\text { [A21] } \quad i_{\alpha}^{i}=-D_{\alpha}^{i} \nabla \omega_{\alpha}^{i} \quad i=\mathrm{w}, \mathrm{a} ; \quad \alpha=1, \mathrm{~g}
$$

In particular, for the vapour transfer the following model is used:

[A22]

$$
\begin{aligned}
& \boldsymbol{i}_{\mathrm{g}}^{\mathrm{w}}=-\left(\phi \rho_{\mathrm{g}} S_{\mathrm{g}} \tau D_{\mathrm{m}}^{\mathrm{w}} \boldsymbol{I}+\rho_{\mathrm{g}} \boldsymbol{D}_{\mathrm{g}}^{\prime}\right) \nabla \omega_{\mathrm{g}}^{\mathrm{w}} \\
& D_{\mathrm{m}}^{\mathrm{w}}=5.9 \times 10^{-12} \frac{(273.15+T)^{2.3}}{P_{\mathrm{g}}} \quad\left(\mathrm{m}^{2} / \mathrm{s}\right)
\end{aligned}
$$

where $\tau=0.8$; more details can be find elsewhere (e.g., Olivella et al. 1994; Technical University of Catalonia 2011).

\section{Constitutive models related to the thermal behaviour}

Fourier's law has been adopted to describe the conductive flux of heat. The thermal conductivity $(\lambda)$ depends on the saturation of the clay and is expressed by the geometric mean of the thermal conductivities of the components

$$
\begin{array}{ll}
{[\mathrm{A} 23 a]} & \boldsymbol{i}_{\mathrm{c}}=-\lambda \nabla T \\
{[\mathrm{~A} 23 b]} & \lambda=\lambda_{\mathrm{sat}}^{S_{1}} \lambda_{\text {dry }}^{\left(1-S_{1}\right)}
\end{array}
$$

Based on experimental results (Fig. $5 d$ ), the following thermal conductivities have been adopted: $\lambda_{\text {dry }}=0.47\left(\mathrm{~W} / \mathrm{m} \cdot \mathrm{C}^{\circ}\right)$ and $\lambda_{\text {sat }}=1.15\left(\mathrm{~W} / \mathrm{m} \cdot \mathrm{C}^{\circ}\right)$.

\section{Equilibrium restrictions}

It is assumed that phase changes are rapid in relation to the characteristic times typical of the problem under consideration. So, they can be considered in local equilibrium, giving rise to a set of equilibrium restrictions that must be satisfied at all times. The vapour concentration in the gaseous phase is governed by the psychrometric law and the amount of air dissolved in water is given by Henry's law (Olivella et al. 1994, 1996).

\section{Stress invariants}

The stress invariants are

$$
p=\frac{1}{3}\left(\sigma_{x}+\sigma_{y}+\sigma_{z}\right)
$$

$$
J^{2}=\frac{1}{2} \operatorname{trace}\left(s^{2}\right)
$$

$$
\theta=-\frac{1}{3} \sin ^{-1}\left(1.5 \sqrt{3} \operatorname{det} s / J^{3}\right)
$$

with

[A27] $\boldsymbol{s}=\boldsymbol{\sigma}-p \boldsymbol{I}$

where $\boldsymbol{I}$ is the identity tensor.

\section{References}

Alonso, E.E., Gens, A., and Josa, A. 1990. A constitutive model for partially saturated soils. Géotechnique, 40(3): 405-430. doi:10. 1680/geot.1990.40.3.405.

Gens, A. 1995. Constitutive laws. In Modern issues in non-saturated soils. Springer-Verlag. pp. 129-158.

Gens, A., Sánchez, M., Guimarães, L., Alonso, E.E., Lloret, A., Olivella, S., Villar, M.V., and Huertas, F. 2009. A full scale in situ heating test for high level nuclear waste disposal. Observations, analysis and interpretation. Géotechnique, 59(4): 377-399. doi:10. 1680/geot.2009.59.4.377.

Lloret, A., Villar, M.V., Sánchez, M., Gens, A., Pintado, X., and Alonso, E.E. 2003. Mechanical behaviour of heavily compacted bentonite under high suction changes. Géotechnique, 53(1): 2740. doi:10.1680/geot.2003.53.1.27.

Olivella, S., Carrera, J., Gens, A., and Alonso, E.E. 1994. Nonisothermal multiphase flow of brine and gas through saline media. Transport in Porous Media, 15(3): 271-293. doi:10.1007/ BF00613282.

Olivella, S., Gens, A., Carrera, J., and Alonso, E.E. 1996. Numerical formulation for a simulator (CODE-BRIGHT) for the coupled analysis of saline media. Engineering Computations, 13(7): 87112. doi:10.1108/02644409610151575.

Technical University of Catalonia. 2011. CODE_BRIGHT user's manual. Technical University of Catalonia.

van Genuchten, R. 1978. Calculating the unsaturated hydraulic permeability conductivity with a new closed-form analytical model. Water Resources Research, 37(11): 21-28. 